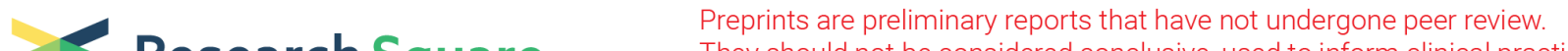 Research Square They should not be considered conclusive, used to inform clinical practice, or referenced by the media as validated information. \\ Market Risk Model agricolture portfolio value-at-risk \\ Giulio Carlone ( $\nabla$ giulio.carlone@ieee.org ) \\ Oxford University https://orcid.org/0000-0002-6923-1726
}

\section{Research Article}

Keywords: Market Value at Risk, Risk Analysis, Bank Authorities, Parametric Approach, Semi Parametric Approach, Non Parametric Approach, Parametric Approach, Price Observations, Commodity Portfolio

Posted Date: July 27th, 2020

DOl: https://doi.org/10.21203/rs.3.rs-46262/v1

License: (c) (1) This work is licensed under a Creative Commons Attribution 4.0 International License. Read Full License 


\title{
Market Risk Model agricolture commodity portfolio value-at-risk
}

\author{
dr Giulio Carlone \\ Giulio.Carlone@gmail.com \\ Giulio.Carlone@ieee.org \\ ORCID iD 0000-0002-6923-1726 \\ Oxford University Press Review of Finance Membership 000082633232 \\ American Risk and Insurance Association Membership N9002629731 \\ IEEE Membership 96064659 \\ IEEE Membership 92931269 \\ University College London Computer Science Alunni Membership ID:8-10313282
}

\begin{abstract}
Thinking about this current extreme scenario of stock exchange observed in a world scenario perspective and the related choices for worldbank portfolio investments in Agricolture commodity, this study its based in an advanced economic observation and analisys of the Agricolture commodity in a scenario of portfolio diversification without have the market risk default. This study its based in an advanced financial strategy to define the market model composed of London stock exchange agricolture commodity observed first in a London scenario and second in a Europe scenario and finally in a world scenario. The authorities regulation and the requirements used to define, the mathematical point of view and to describe, the market value at risk point of view, have been standardized in this empirical market model. The commodity scenario observed and the empirical market model defined to observe the max price distortions of the agricolture commodity defined and defined to observe the porfolio value at risk, are in this market model well described and standardized. Authorities are interested in the empirical market model to observe the VaR data because they are interested in a bank's ability to withstand extreme events. VaR is monitored and is sanctioned by regulators defined in the Basel accords. The observed price are used in a variable choice of number of data price observation of five price for week a data price observation of one prices for week and a data price observation of two price for week and further similar strategies . INTRODUCTION
\end{abstract}


This study related a current stressed market use a description of a portfolio composed of London stock exchange agricolture commodity. The study completely based on market risk [2] , [23] , [ 24] , [25], [30] particularly value at risk [4] , [8], [12] , [27] in a London price scenario.

Analizing the market value at risk from a point of view of Autorities , BANKITALY, EBA, ECB , ESMA are described the bank authorities guidelines and are identified the requirements to define a mathematical point of view for describe the market value at risk from a parametric approach of VAR, from a semi parametric approach of VAR, from a non parametric approach of VAR. The list of rules related the Market Risk cames from the European Commission [6] , [7] , [9] , [10] , [29] , [31] , [32] , [39] , [40] , [41] , [42], and the European Securities and Markets Authority [14], and the Italian Stock Exchange [13] , [36] [1] , [5] , [11] , [15] , [16 ] . The proposal market risk model, is able to generate a risk management scenario to observe the VAR distorsions using differents confidence levels of the real commodity portfolio to observe the max price distorsion the close price the high price in a first commodities and the agricolture commodity portfolio VAR.

The list of prices for data observations start from a case of 37 price observations and a case of 49 price observations. and a real large case of 244 prices used for VAR data generation. The study is complete related concerns over the transparency and negotiations to prevent negative side effects [19] [17], [18], [20], [21], [26], [33], [35], [37], [38] .

The complete scenario of the max price distortions of this portfolio commodity price and the agricolture commodity porfolio var have been standardized in a empirical market model and this model have been generalized in london stock exchange and in europe stock exchange and world stock exchange.

The conclusion are related the eu regulation and rules used from monitor and observe the generation of this empirical market model for var data generation [43] . this is a rule monitored by authoruty to observe the market default . 


\section{PORTFOLIO MAIN CHARACTERISTIC STRUCTURE OF LONDON STOCK EXCHANGE COMMODITY COUNTERPARTY}

The portfolio structure of London counterparty .

The commodity portfolio analysed is part of the London stock exchange . The strategy consists in selling or buying just after a daily evaluation of the resulting value at risk.

In this study, using a probability of $99 \%$, we still have higher values from the parametric evaluation and lesser ones from the semi parametric evaluation and, in ten sets of observation days we still get five total decreases and one total increase .

Matching the first part of total increasing and decreasing data with the second part of total increasing and decreasing data we obtain a result of final var data using a invetment strategies .

This is a study of market risk in a portfolios of two commodities .

A second step is the portfolio analisy in other city or stock exchange. In this specific case of study gives similar results for the two portfolios. This is probably because they contain similar commodity products .

\section{MARKET VALUE AT RISK ANALYSIS FROM A POINT OF VIEW OF SUPERVISORS BANKITALY , EBA , ECB , ESMA.}

The positive effect is the standard Autority monitoring of market risk default .

The negative effect is the requirement of daily update of data requirements for VaR data generation and VaR data monitoring.

Committee of Banking Supervision is revising a diverse list of topics including the standardised and internal models approaches for calculating capital requirements of all risk types.

A perspective of VAR from a point of view of supervisors . The industry already summarises these revisions under the term of these supervisors.

Economic capital is the amount of capital required to absorb potential losses. Value at risk 
models calculate market risk exposure at a level of confidence that is selected by the user.

Bankitaly , EBA , ECB , ESMA sets a 99\% confidence level. The best-practice approach then is to calculate at $99 \%$, so that a bank does not underestimate its risk exposure in the event of extreme market moves or crashes. VaR is monitored and is sanctioned by regulators in the Basel II and Basel III accords.

ISDA In providing guidelines for calculating IM levels for non-cleared contracts, regulators have adopted as a benchmark an approach used by some central counterparties, which determines IM levels based on the market risk exposure of the position, defined as a $99 \%$ value-at-risk over a fixed liquidation horizon that depends on the asset class. Regulatory guidelines recommend the use of a 10-day horizon for non-cleared derivatives, as opposed to 3 or 5 days for cleared OTC contracts, based on a perceived higher risk of non-cleared transactions.

\section{BANK AUTHORITIES GUIDELINES}

The European Securities and Markets Authority published an orientation for clients who want to start using automatic trading systems on the Stock Exchange. These guidelines are aimed at reorganizing earlier systems for automatic trading, explaining what these systems are and illustrating what opportunities exist for clients' direct access to the market.

This orientation follows the guidelines of the MIFID directive, because electronic stock market systems must respect MIFID rules. The platforms used in the market must include controls such as: a governance for developments and the initiation of the control suite; the necessary tests for verifying the correct functioning of the control suite; the required procedure for data back-up; the procedure for making a back up of the automatic trading system on a different site and how to manage functions on this other site. One of the requirements for introducing a system of automatic 
trading is a transparency tool for the development and control of the system. When using algorithms in stock exchange platforms, using $\mathbf{X M L r u l e}^{1}$ files

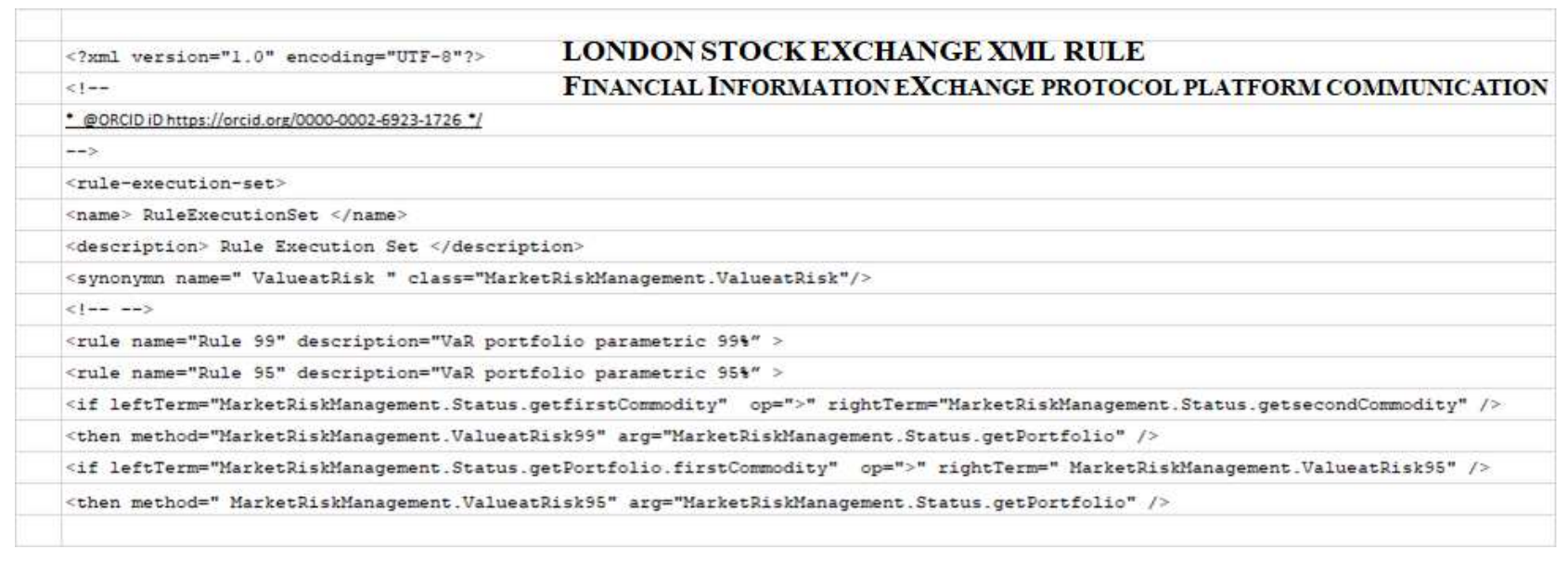

\section{FIGURE 1 : VAR RULESET XML FILE LSE}

for automatic trading systems, the client has to build a transparency back environment to carry out simulations and tests.

European community: The MiFID directive 2014/65/UE and rule UE MiFIR 600/2014 were published and applied soon after the financial crisis. MiFID and MiFIR are part of MiFID II, and they reorganize regulations of the stock market and other places where trading is carried out. MiFID

\footnotetext{
${ }^{1}$ LONDON STOCK EXCHANGE XML RULE Financial Information eXchange protocol platform communication

London stock exchange provides a FIX trading gateway that enables member firms to submit orders and/or quotes and to receive real-time information on executed trades. The interface is a point-to-point service based on technological and industrial standards TCP/IP, FIXT and FIX.

Connection methods and message components from the administrative side

In order to connect to the Millenium platform you have to make a connection to the IP address in the respective port name using the Financial Information eXchange protocol (FIX) and the Transmission Control Protocol/Internet Protocol (TCP/IP) for communication. Connecting to the Millenium platform requires a few operations from the administrative side: test request, logon, logout, sequence reset, resend request, reject, and heartbeat: Test request allows the client or the server to request a response from the other party if inactivity is detected. Logon establishes a connection between client and server. Logout allows the termination of a connection between client and server. Sequence reset enables the client or server to increase the sequence number expected to arrive to the other side. Resend request allows the recovery of lost messages following a malfunction of the layers of communication. Reject is a message used to reject non-conforming elements. Heartbeat allows the client and the server to test the communication line during periods of inactivity and to verify that the interfaces are available at both ends.

Data transmitted with the fix protocol

The following string is an example of a fix message. A header, a body and a final part compose the string. This string shows a quote for the individual instrument USD/CAD at 15:25:20 GMT on January 21, 2013: 8=FIX.4.2 | 9=309 | 35=S | 49=ML-FIX-FX | 56=ECHO2-QTS-TEST | 34=5015 | 52=20130121-15:25:20 |131=1185895365 | 117=ECHO2-QTS-TEST.00043690C8A8D6B9.00043690D14044C6 | 301=0 |55=USD/CAD | 167=FOR | 15=USD | 132=1.065450 |133=1.065850 | 134=5000000.0 | $135=5000000.0|647=2000001.0| 648=200000.0|188=1.06545| 190=1.06585|60=20130121-15: 25: 20| 40=\mathrm{H}|64=20130122| 10=178:$

Order management client side

In order to manage an order from the customer side we have the following choices: With regards to the management of quotes from the customer's perspective, the phase of sending a request can be: quote; quote cancel. Quote allows the client to submit a quote for a single instrument. Quote cancel allows the client to cancel a quote for a particular instrument. Order cancel request allows the customer to cancel an order in real time. Order mass cancel request allows the customer to cancel all orders in real time for a particular segment. The mass cancellation can be applied to a specific batch of orders, or to all orders coming from the client. Order cancel/replace request allows the customer to cancel/replace an order in real time. New order-single; cancel order request; order mass cancel request; order cancel/replace request; cross new order message; cross-order cancel request. New order-single allows the customer to submit a new order. New order cross message allows the customer to place an order on the Cross/Block Trade Facility. Cross order cancel request allows the customer to cancel an order on the Cross/Block Trade Facility. Quote management server side

From the server side the most common responses to receiving a message from the client for the management of quotes are the following: quote status report, mass quote acknowledgement, execution report. Quote status report indicates one of the following: Quote accepted, Quote rejected, Quote expired, Request to cancel a single quote accepted, Request to cancel a single quote rejected, Quote cancelled by Market Supervision; Mass quote acknowledgement indicates one of the following: Request to mass cancel quotes accepted, Request to mass cancel quotes rejected. Execution report indicates one of the following: Quote executed, Trade cancelled. When the client's side sends messages, the answers to these messages from the server side are: execution reports; order cancel reject, and order mass cancel report. Execution report indicates one of the following actions: order accepted, order rejected, order executed, order expired, order cancelled, order cancelled/replaced exchange deleted, order suspended, order active; Order cancel reject indicates that the cancellation request or the request for cancellation/replacement was rejected;

Order mass cancel report indicates one of the following actions: the order of mass cancellation was accepted; the mass cancellation was rejected.
} 
II expands the number of financial instruments previously checked by MiFID, and tries to ensure that stock exchanges are carried out on a well-organized market platform. It also introduces rules to better manage high frequency trading. It improves transparency and the control of financial markets, including the derivatives market. It addresses the issue of volatility of prices of derivatives in commodities.

The standardization by european Regulations of the Empirical Market Model applyed on VaR scenario for monitoring and supervision have implication for risk perspective of the results for the definition of a Consultation Response related the Prudential Regulation Authority for EBA for ISDA for ECB for ESMA.

\section{RISK MANAGEMENT SCENARIO}

Effective risk management in trading operations is as important as the signals that trigger purchases. The proper functioning of a well-designed and executed risk management strategy is the key to sustained profitability in all organizations. Risk management in relation to high transaction frequency trading is particularly important since it can reduce potentially large losses to minimal ones. I will show what strategies for risk measurement there are and the specific risks an organization faces in relation to high frequency trading. Approaches to risk measurement can be divided into four broad categories.

First, statistical models, which generate estimates of the worst future outcome based on past information, is the preferred methodology to estimate risk if the conditions allow for their use.

Second, scalar models establish maximum levels of expected loss rates using business parameters such as revenue and operating costs.

Third, scenario analysis determines a base for the best and the worst-case scenario, depending on risk indicators , Key Risk Indicators, Kris , finally, random modelling seeks to identify the causes and effects of potential losses. 
There are a number of risks that an organization faces with Algorithmic Trading: market risk corresponds to the risk of losses from fluctuations in market prices; credit risk corresponds to the risk that a borrower will default on any type of debt, thus avoiding making the payment due; counterparty risk corresponds to the risk that the counterparty fails to fulfil its obligations under an agreement; liquidity risk, or the risk of being unable to sell an asset in good time; operational risk, defined as the risk relating to the internal workings of an organization, and which are within its control; and legal risk, referring to the risk associated with the impact of a defect in legal documentation which could negatively impact cash flows or debt service capability. Market risk can be defined as the risk of losses in on and off-balance sheet positions arising from adverse movements in market prices.

\section{MATHEMATICAL POINT OF VIEW OF MARKET VALUE AT RISK, PARAMETRIC APPROACH OF VAR, SEMI PARAMETRIC APPROACH OF VAR, NON PARAMETRIC APPROACH OF VAR}

The Value at Risk (VaR) is a statistical measure of risk. It measures risk through a probability distribution of potential profits and losses. This measure is particularly useful for investors analysing the risk of a portfolio because it makes a correlation between different financial instruments and the probability that certain return scenarios occur.

VaR is defined as a measure of the maximum "potential" loss that a portfolio may incur within a statistical framework over a given period of time.

$\mathrm{VaR}$ is dependent on the temporal horizon. It is up to the investor to decide whether to use one day, 10, or any other length of time. It also depends on the selected probability. Normally this is $95 \%$ or $99 \%$, but again it is up to the investor to choose. The unit of measure, VaR, is expressed as the absolute value of the base currency chosen by the investor. VaR has a number of significant advantages over traditional risk measures: it provides a common consistent measure of risk across different positions and risk factors; VaR can be applied to any type of portfolio, and it enables us to compare the risk of different portfolios; It allows us to measure the risk associated with a fixedincome position, for example, in a way that is comparable to the risk associated with an equity 
position; VaR enables us to aggregate the risk of a subposition into an overall measure of portfolio risk, and in so doing, to take into account the ways in which different risk factors interact with each other; VaR is probabilistic, and gives risk managers useful information on the probabilities associated with specified losses; $\mathrm{VaR}$ is expressed in the simplest and most easily understood unit of measure, namely lost money.

\section{PARAMETRIC APPROACH OF VAR}

Models such as RiskMetrics and GARCH propose a specific parameterization for the behaviour of prices. The family of ARCH models was introduced by Engle and Bollerslev and has been successfully applied to financial data. See Bollerslev, Engle and Nelson for further reading. For Jun QI the Monte Carlo Simulation method covers a wide range of possible values in financial variables and fully accounts for correlation. We can draw a large number of scenarios randomly and price the portfolio for each one. Monte Carlo Simulation is generally used to compute VaR for portfolios containing securities with non-linear returns. The main difference between Monte Carlo Simulation and Historical Simulation is that instead of using historical observations, Monte Carlo Simulation chooses a statistical model that is believed to adequately capture or approximate the possible changes in the market.

The general steps of the Monte Carlo method are as follows:

1. Identify or select a suitable model for the changes in market factors.

2. Estimate the parameters.

3. Generate $n$ random variables to obtain the simulated changes in market factors over a time horizon.

4. Select the $\alpha$-th quantile of the observation.

5. Estimate the VaR based on the current price. 
Market risk models have been developed that allow us to quantify, compare and aggregate the risk associated with individual items or entire portfolios. These are models of Value at Risk (VaR), corresponding to the measure of the maximum loss that a position or a portfolio of positions can undergo. We consider a parametric measurement approach of market risk.

The formula for calculating the $\mathrm{VaR}$ of a portfolio $\mathrm{P}$ of $\mathrm{N}$ positions with a parametric approach is the following:

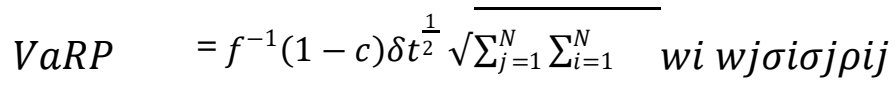

Where:

$\mathrm{N}=$ number of positions;

$\sigma_{i}=$ Volatility of the i-th position;

$\rho_{i j}=$ Coefficient of correlation between the positions of the $\mathrm{i}$-th and $\mathrm{j}$-th;

$w_{i}=$ Fraction of wealth invested in the i-th position;

$f^{-1}=$ Inverse of the standard normal cumulative distribution function; $\mathrm{c}=$ confidence interval;

$\delta t^{\frac{1}{2}}=$ Time interval.

Since we have to constantly monitor the value of $\mathrm{VaR}$, we must therefore constantly monitor the value of the parameters that form part of its calculation. In this regard, we must take into consideration the calculation of volatility, which is expressed by the following formula:

$$
\begin{gathered}
\sum t \underline{i=-\underline{t} 1-n} \underline{\operatorname{ri} 2} \\
\sigma t=\sqrt{ }{ }_{n-1}
\end{gathered}
$$


Where the variables are as follows: $r_{i}=\mathrm{i}$-th value, observed at time $\mathrm{t} ; \mathrm{n}=$ number of observations.

\section{SEMI PARAMETRIC APPROACH OF VAR}

Recently, alternative methods to estimate Value at Risk have been proposed such as applications of Extreme Value Theory and applications of regression quartile technique as in Chernozhukov and Umantsev and Engle and Manganelli. Other approaches that can be mentioned in this section are those based on Bollerslev and Woolridge quasi-maximum likelihood GARCH, as suggested by Diebold, Schuermann and Stroughair, and independently implemented by McNeil and Frey and Engle and Manganelli. A similar idea can be found in Hull and White, although their model is not as robust as those cited above, since the variance is not estimated using QML GARCH.

With the approach of Jun QI, the Variance-Covariance model, or delta-normal, is based on the assumption that returns are normally distributed on a linear approximation of the portfolio.

The $\mathrm{VaR}$ is then given by

$$
V a R^{\alpha}=Z_{\propto} \pi \sqrt{\sum_{i=1}^{N} \sum_{J=1}^{N} \omega_{i} \omega_{j} \sigma_{i, j}}
$$

where wi and wj denote the weight of assets $i$ and $j$ in the portfolio; $\sigma i, j$ denotes the covariance and $Z \alpha$ denotes the one-side confidence level for cumulative normal distribution of portfolio returns. For example, under the normal distribution, the quantile $Z \alpha=1.65$ if $\alpha=95 \%$.

The covariance between two assets is

$$
\sigma i, j=\rho i, j \sigma i \sigma j
$$


where $\rho \mathrm{i}, \mathrm{j}$ denotes the correlation and $\sigma i$ the volatility of asset $i$. One of the most famous VarianceCovariance models is RiskMetrics by J.P. Morgan. The advantage of the Variance-Covariance approach is that it simplifies $\mathrm{VaR}$ calculations because it assumes all percentiles to be known multiples of the standard deviation. However the assumption that the data is normally distributed is not consistent with real-world observations, which could lead to an underestimation of the VaR.

Šime Čorkalo's perspective of the Variance-Covariance method is also known as Linear VaR or Delta normal VaR. This approach is relatively simple and is widely used. This method includes parts of Harry Markowitz's modern portfolio theory, taking into account the correlation coefficients between assets.

Historical data is used to calculate the main parameters: mean, standard deviation, correlation. This method calculates VaR by assuming some theoretical distribution of asset returns. Usually normal distribution is used. This assumption allows volatility to be described in terms of standard deviations (SD). Another advantage of normal distribution is that it can be described by its first two moments: mean, and standard deviation (Žiković, 2005). This distribution is symmetrical so skewness is 0 and kurtosis 3. If we want to find the position of a random variable $(\mathrm{X})$ in a normal distribution we use the standard value of variable $\mathrm{Z}$ (Z-score).

Every variable can be transformed into a standard variable with this formula:

$$
\mathrm{X}=\mu+\mathrm{z} \sigma
$$

where $\mathrm{z}$ is simply calculated as $\mathrm{Z}=\mathrm{X}-\mu / \sigma, \mu-$ mean , $\sigma-$ standard deviation . In a similar way VaR can be calculated as a multiple of standard deviation.

III. NON PARAMETRIC APPROACH OF VAR 
One of the most common methods for VaR estimation is the Historical Simulation. This approach drastically simplifies the procedure for computing the Value at Risk, since it doesn't make any distributional assumption about portfolio returns. Historical Simulation is based on the concept of rolling windows. First, one needs to choose a window of observations that generally ranges from 6 months to two years.

If such a number falls between two consecutive returns, then some interpolation rule is applied.

To compute the VaR the following day, the whole window is moved forward by one observation and the entire procedure is repeated. Even if this approach makes no explicit assumption on the distribution of portfolio returns, there is an implicit assumption hidden behind this procedure: the distribution of portfolio returns doesn't change within the window. Several problems derive from this implicit assumption.

The perspective of Jun QI on Historical Simulation is the most common and simplest estimation of VaR. The main advantage of the Historical Simulation approach is that it is non-parametric which means the data does not have to follow a specific distribution. However, Historical Simulation assumes that the changes in financial market conditions today are the same as those that took place in the past :

- The Historical Simulation method can be applied in the following way:

- Obtain the historical market price for a chosen time period.

- Calculate the asset returns and then sort them in ascending order.

- Select the $\alpha$-th quantile of the observation.

- Estimate the VaR based on the current price.

The most important element in the Historical Simulation method is the rolling window. The size of the window can affect the estimation results of the VaR. For Stanford University, Historical Simulation is a good resampling method because of its simplicity and lack of distributional assumptions about the underlying process of returns. It is based on the assumption that history repeats itself. Unlike other parametric methods, the historical simulation makes no specific distribution 
assumption about return distributions. However, the historical simulation implicitly assumes that the distribution of past returns is a good and complete representation of expected future returns. This method also relies on a specific short historical moving window. The bootstrap historical simulation approach is an extension of traditional historical simulation. It is a simple and intuitive estimation procedure. The bootstrap technique draws a sample from the data set, records the VaR from that particular sample and Jreturns" the data. This procedure is repeated over and over and records multiple sample VaRs. Since the data is always returned to the data set, this procedure is like sampling with replacement.

The best VaR estimate from the full data set is the average of all sample VaRs.

\section{VAR DISTORSIONS USING DIFFERENTS CONFIDENCE LEVELS REAL PORTFOLIO CASE 244 SIMULATION DATES AND PRICES}

The teorical description of the effect of the var during the variable prices in market value at risk should be managed - using initial variation margins $(100-\alpha) \%$. Initial margins were set VAR value from a different perspective and side . 


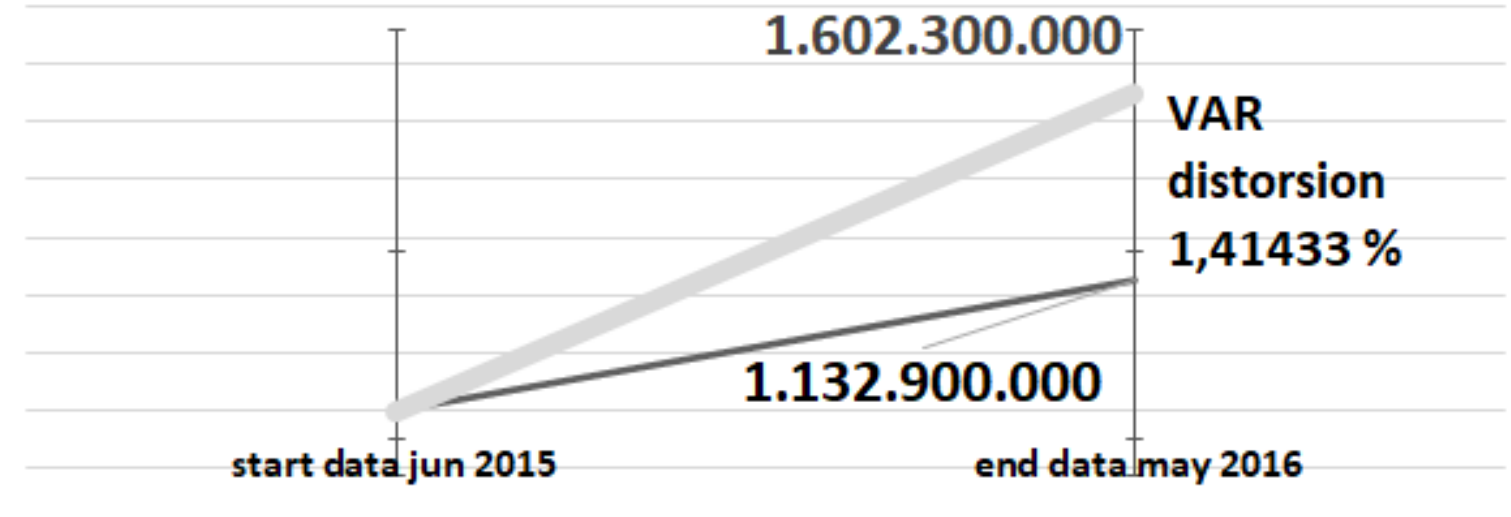

FIGURE 2: INITIAL VAR DATA GENERATED AND DISTORSION REQUIREMENTS

We are refered to the observation of the market in London Stock Exchange . In this study are examined the confidence lever, the default probability. In a first case a risk default of $5 \%$ and in a second case a risk default of $1 \%$. The portfolio of study is composed of commodities . Two commodities from the London Stock Exchange.

The LSE market evidence in this study is related the generated value of VAR at $99 \%$ level of confidence and the LSE market evidence in this study is related the generated value of VAR at $95 \%$ level of confidence.

This is the real graphical results of the described market .

The very large VaR value of my portfolio of commodity, is identified in case of $99 \%$ of confidence level . 
The number of simulation dates used for the VaR evaluation are in a bse case of representation of 37 simulation dates and the reled graph is the

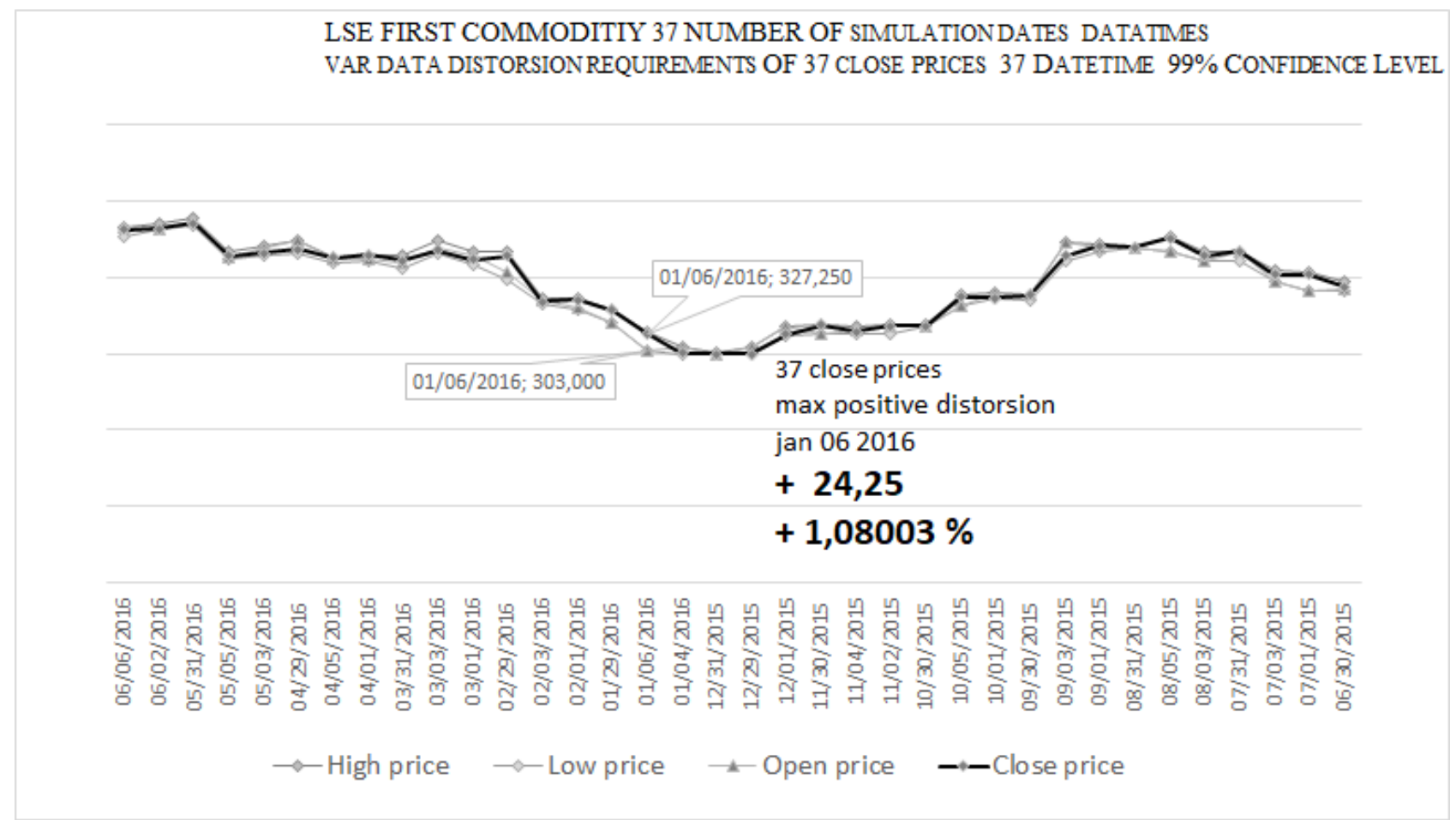

\section{FIGURE 3 : FIRST COMMODITY 37 CLOSE PRICES SCENARIO}

The second case of study is using a number of simulation dates used for the VaR evaluation are in a base case of representation of 49 simulation dates and the related graph is the 


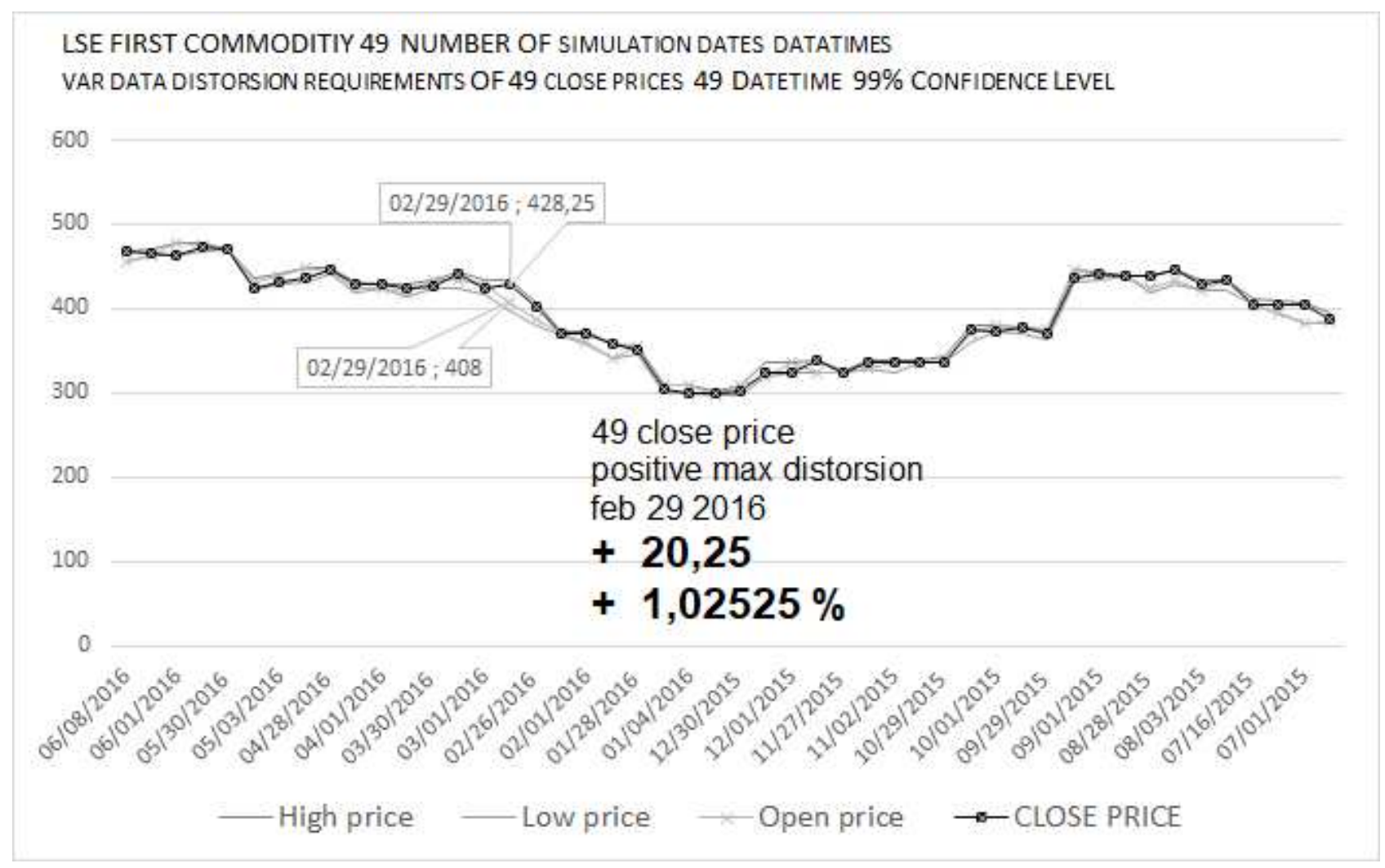

\section{FIGURE 4 : FIRST COMMODITY 49 CLOSE PRICES SCENARIO}

the next one is the generalization and the study of my test portfolio composed of two commodities studyed use this first one year commodity prices

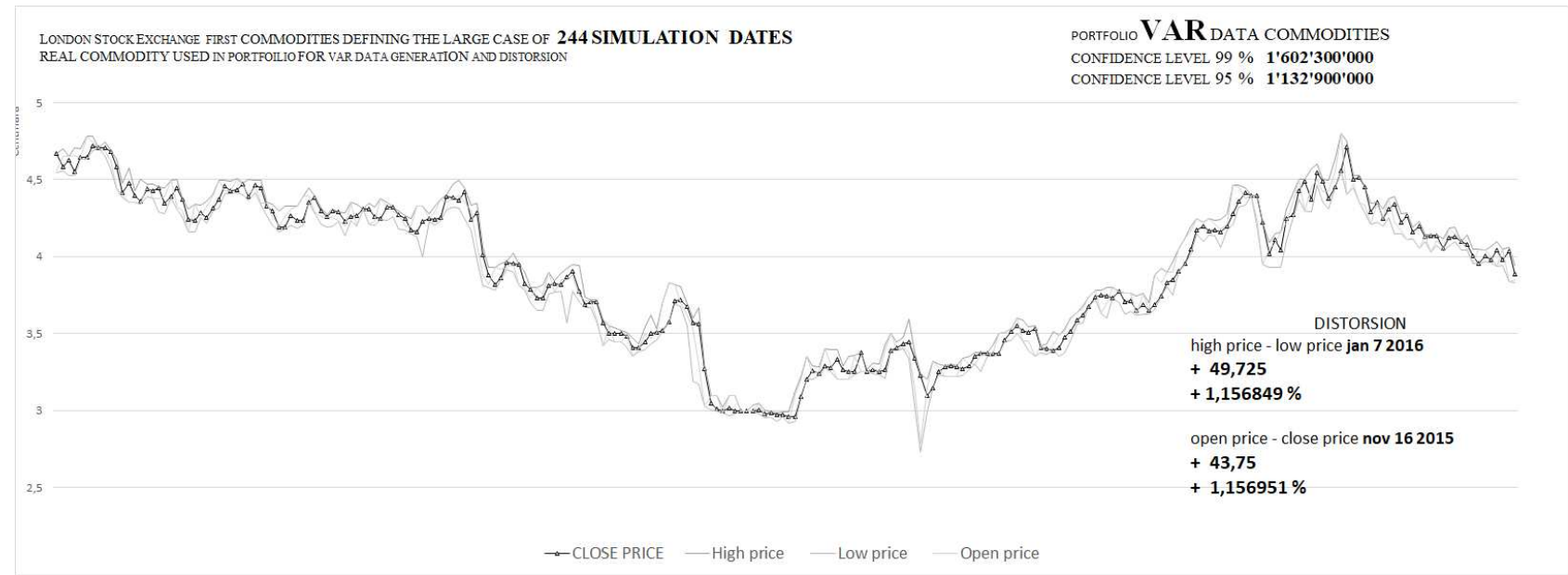

FIGURE 5 : PORTFOLIO FIRST COMMODITY 244 CLOSE PRICES SCENARIO

this is the second commodity of one year prices 


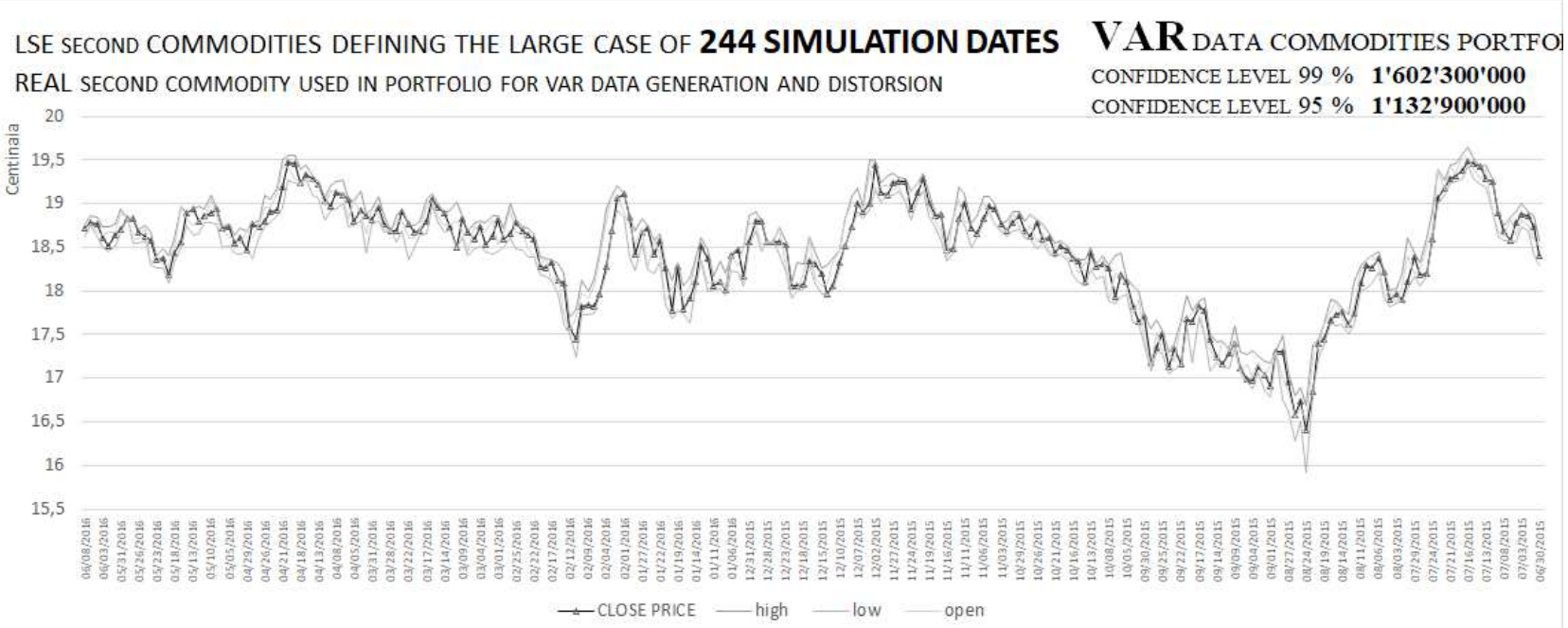

FIGURE 6 : PORTFOLIO SECOND COMMODITY 244 CLOSE PRICES SCENARIO

COMPLETE SCENARIO OF MAX PRICE DISTORTIONS. COMMODITY PRICE MANIPULATION DISTORTIONS IN RISK, MANAGEMENT, RISK MANAGEMENT.

Balance of first portfolio commodity high and low price evidences in one year of observing

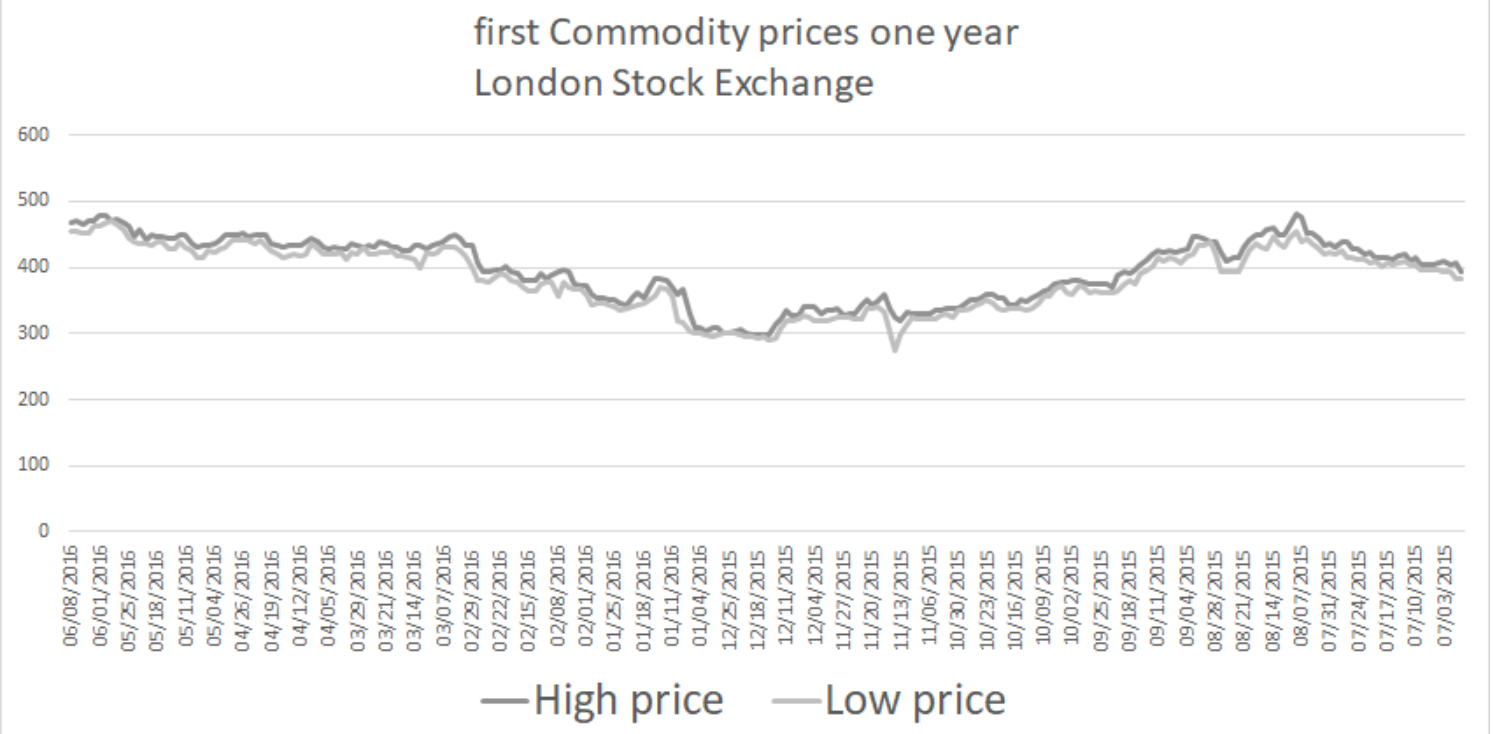

FIGURE 7 : FIRST LSE COMMODITY 244 HIGH PRICES AND LOW PRICES IN ONE YEAR

Investors side details of price evidence, first portfolio commodity , max distance, high and low price evidences in one year of observing from 2015 to 2016, the max distance is in november 2015 
LONDON STOCK EXCHANGE FIRST COMMODITIES DEFINING THE LARGE CASE OF 244

SIMULATION DATES

REAL COMMODITY USED IN PORTFOILIO FOR VAR DATA GENERATION AND DISTORSION

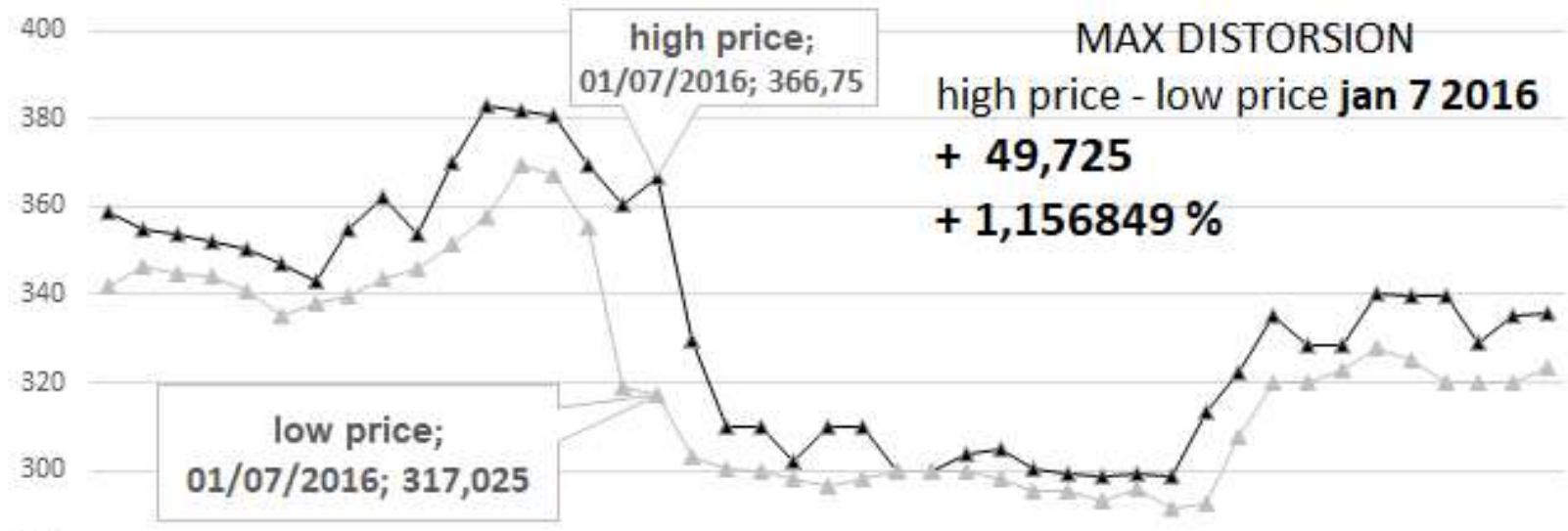

280

$\rightarrow$ high price $\rightarrow$ low price

FIGURE 8: FIRST COMMODITY LSE 244 HIGH PRICES AND LOW PRICES, MAX DISTORTION, IN ONE YEAR

\section{first commodity CLOSE PRICE MAX DISTORTION \% distorsion $=$ close price - open price}

244 close prices;

1,1569

37 close prices; $\mathbf{1 , 0 8 0 1}$

49 close prices;

1,0252

close price max distorsion

$\rightarrow 49$ close prices $\rightarrow 37$ close prices $\rightarrow 244$ close prices

FIGURE 9: COMMODITY PORTFOLIO LSE CLOSE PRICE MAX DISTORTION, IN ONE YEAR 
EMPIRICAL MARKET MODEL GENERALIZATION IN LONDON IN EUROPE AND WORLD

Related the regulation and rules defined by the European Authority have to be defined a market risk model in a theorical and a empirical observation .

In the first part of this study have be defined the theorical method for the best vAR generation .

In the second part of our study have be defined the empirical genmeration of data end analysis .

This is a generalization and a perspective from a european autority point of view

I. EMPIRICAL MARKET MODEL in London Stock Exchange Scenario

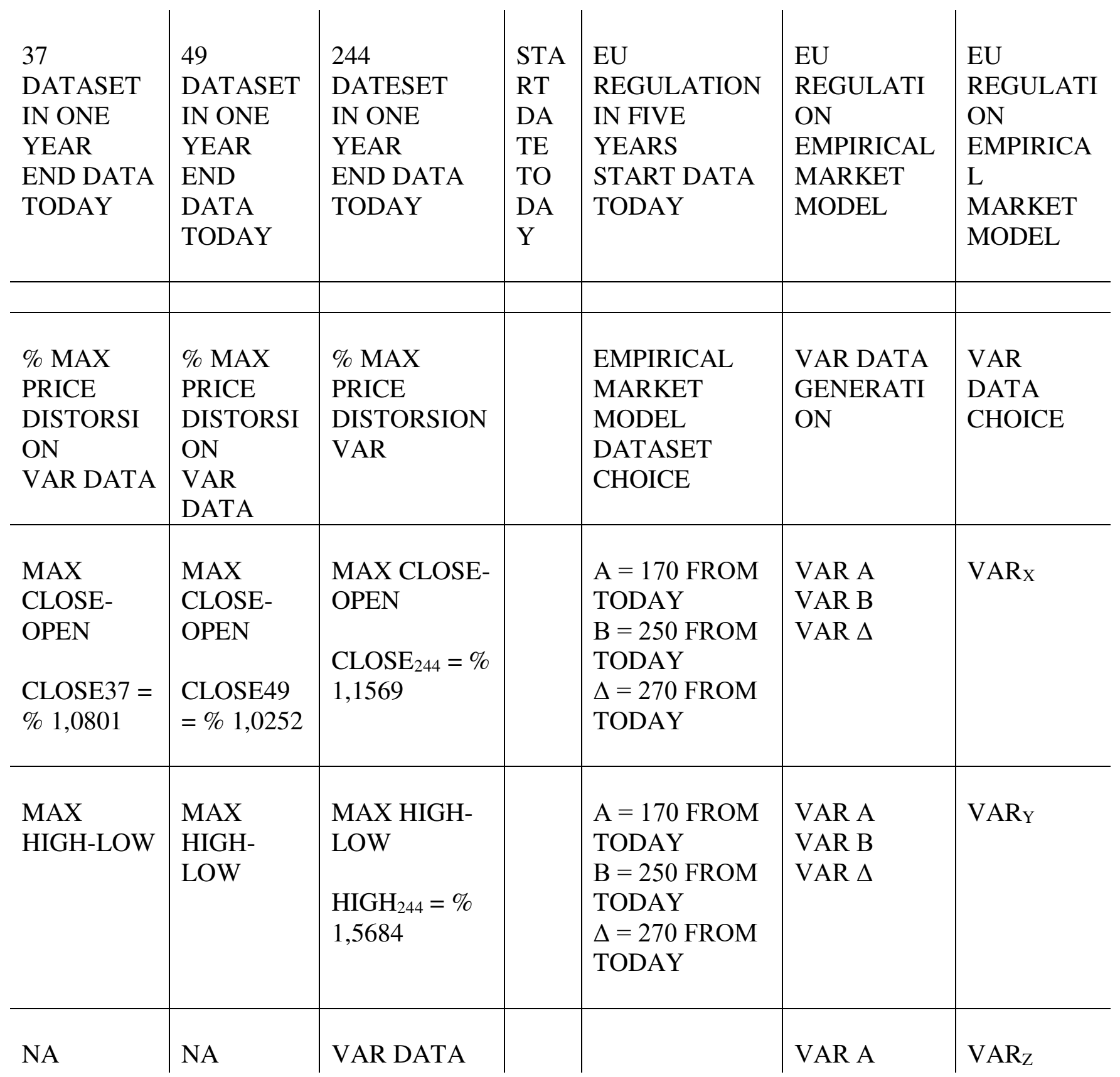




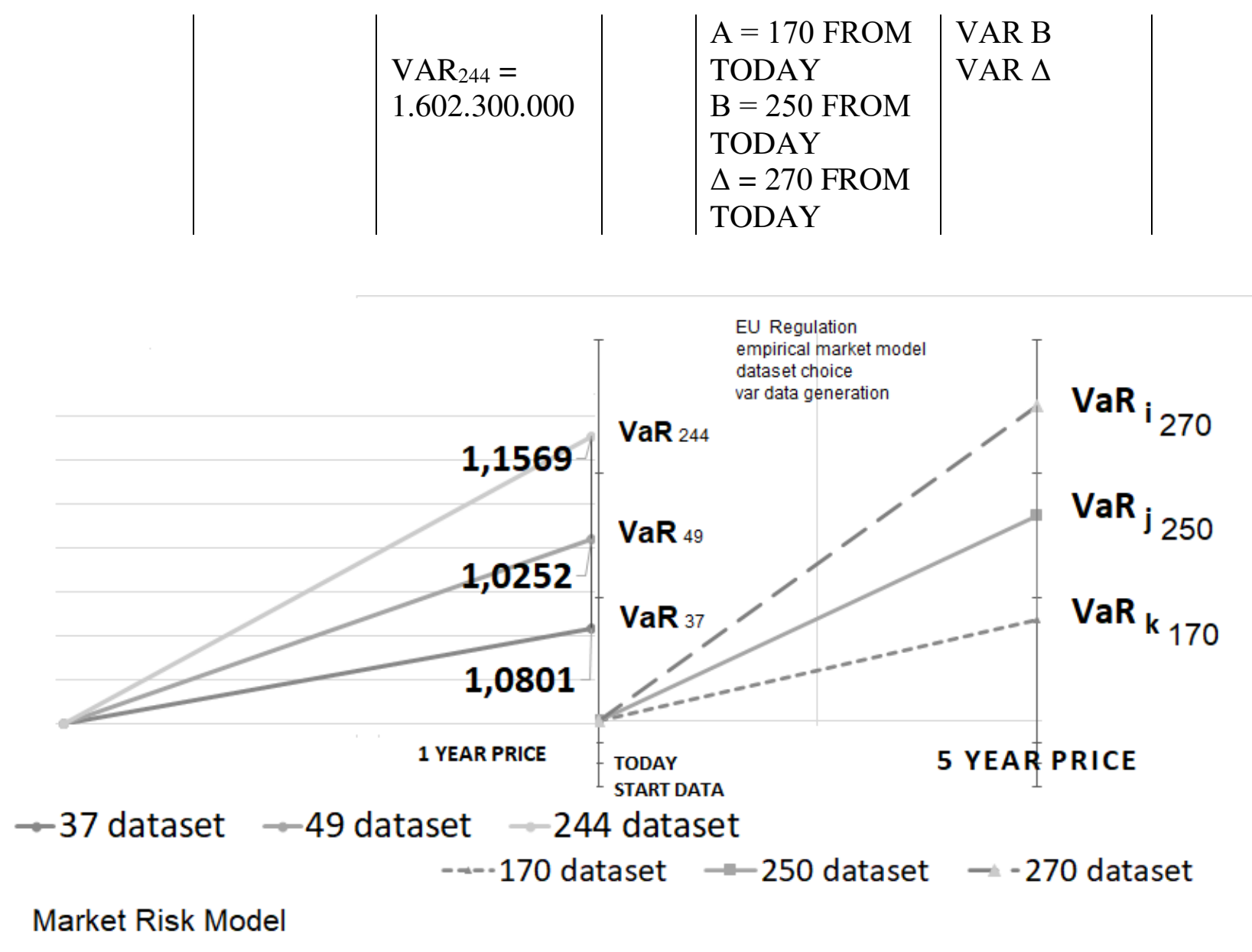

FIGURE 10: SCENARIO EMPIRICAL MARKET MODEL REPRESENTATION

II. EMPIRICAL MARKET MODEL in European Scenario

BANKITALY , EBA, ECB , ESMA, BIS sets a 99\% confidence level. The best-practice approach then is to calculate at $99 \%$, so that a bank does not underestimate its risk exposure in the event of extreme market moves or crashes. This is a European case of study relted the Empirical Market Model defined. 


\section{EMPIRICAL MARKET MODEL APPLYED TO EUROPEAN SCENARIO VAR DATA COMMODITIES PORTFOLIO default $1 \%$}

\begin{tabular}{|l|c|}
\hline & $\begin{array}{c}\text { LSE VAR } \\
\text { commodities } \\
\text { pU REGULATION } \\
\text { EMPIRICAL MARKET MODEL }\end{array}$ \\
\hline $\begin{array}{l}\text { FOR DATASET CHOICE } \\
\text { VAR DATA GENERATION } \\
\text { VAR DATA CHOICE }\end{array}$ & $\begin{array}{c}\text { BRX VAR } \\
\text { commodities }\end{array}$ \\
\hline & $\begin{array}{c}\text { portfolio } \\
\text { MIL VAR }\end{array}$ \\
\hline & commodities \\
\hline & portfolio \\
\hline one year & today \\
\hline
\end{tabular}

FIGURE 11: SCENARIO EMPIRICAL MARKET MODEL EUROPEAN SCENARIO

III. EMPIRICAL MARKET MODEL in a World Scenario

This is a World scenario of my case of study related the Empirical Market Model defined where Bankitaly, EBA, ECB , ESMA, BIS sets a 99\% confidence level.

\section{EMPIRICAL MARKET MODEL APPLYED TO WORLD SCENARIO VAR DATA COMMODITIES PORTFOLIO default $1 \%$}

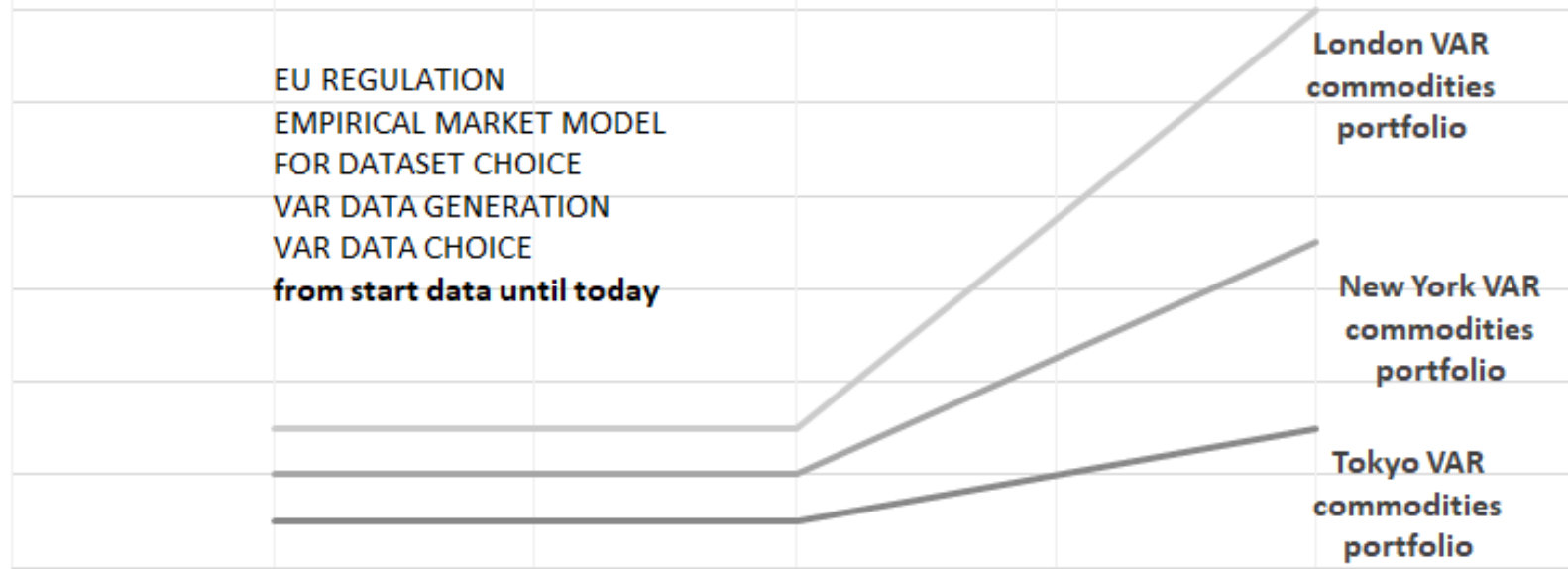

one year

today

five years

FIGURE 12: SCENARIO EMPIRICAL MARKET MODEL WORLD SCENARIO 


\section{CONCLUSION IN POINTS OF EMPIRICAL MARKET MODEL GENERALIZATION}

From a point of view of stock exchange Autorities, in this scenario of a portfolio composed of London stock exchange agricolture commodity our study it is observed the case of default defined in fixed value of one as a confidence level value defined.

From a quantitive point could be found the max value of default observing the VaR value generated using the confidence level defined. Using the market model defined have to be generated a multiple numbers of VaR values using a different number of dataset .

From a point of view of EU Regulation Autorities, The conclusion are related the and rules used from monitor and observe the VaR generation of this empirical market model for var data generation this is a rule monitored by authority to observe the market default .

CONCLUSION, EU REGULATION EMPIRICAL MARKET MODEL FOR DATASET CHOICE VAR DATA GENERATION VAR DATA CHOICE

Economic capital is the amount of capital required to absorb potential losses. Value at risk models calculate market risk exposure at a level of confidence that is selected by the user. A criticism of this is that this confidence level is insufficient, because it does not cover extreme events.

Regulatory authorities are interested in a higher level of confidence because they are interested in a bank's ability to withstand extreme events.

The Empirical Market Model proposed observing the Regulation it is for supervisors monitoring of Bankitaly , EBA , ECB , ESMA, BIS sets a 99\% confidence level. The best-practice approach then is to calculate at $99 \%$, so that a bank does not underestimate its risk exposure in the event of extreme market moves or crashes. Value at Risk is the maximum loss that one will not exceed with a certain probability $\alpha$ within a given time horizon. $\mathrm{VaR}$ has gained considerable importance as a 
main risk measure.

VaR is monitored and is sanctioned by regulators in the Basel II and Basel III accords. Although conceptually rather simple, estimating the $\mathrm{VaR}$ is often challenging. The definition of normality is critical and is essentially a statistical concept that varies by firm and by risk management system. Put simply however, the most commonly used VaR models assume that the prices of assets in the financial markets follow a normal distribution. To implement VaR, all of a commodity portfolio data must be gathered into one centralized database. Once this is complete the overall risk has to be calculated by aggregating the risks from individual instruments across the entire portfolio. VaR generated by th Empirical Market Model proposed is a measure of the volatility of a commodity portfolio. A portfolio containing assets that have a high level of volatility has a higher risk than one containing assets with a lower level of volatility. The VaR measure seeks to quantify in a single measure the potential losses that may be suffered by a portfolio. VaR is therefore a measure of a bank's risk exposure; it a tool for measuring market risk exposure.

There is no one VaR number for a single portfolio, because different methodologies used for calculating VaR produce different results. A risk management department may choose to use a VaR measurement system in an effort to quantify a bank's risk exposure; however, the application itself is merely a tool. Implementing such a tool in no way compensates for inadequate procedures and rules in the management.

The topic of this investments are related the Empirical Market Model proposed applyed to a commodity portfolio with prices on LSE, a couple of commodities used for identify investments strategies based on observations prices and VAR data generated . In a case of investment strategies to be regulated by European Securities Markets Autority . The portfolio composition are a couple of commodity in London Stock Exchange. Although not all the products are comparable at both EU and world level, this document is intended to give an indication on the most recent price developments.

It s not a sofisticate investment its a base case of portfolio composition . The portfolio its composed 
of two counterparty. And the commodities portfolio its not diversified.

The instruments used for this risk management study are data generated by Matlab and observed by the empirical market model proposed and described. The observed price are used in a multiple choice of data, observation of five price for week, observation of one prices for week , observation of two price for week .

\section{REFERENCES}

[1] European Union, Commision Regulation (EC) No 1287/2006. 2006.

[2] European Union, Commission Directive 2006/73/EC. 2006.

[3] European Union, Directive 2004/39/EC of the European Parliament and of the Council. 2004.

[4] European Union, Directive 2014/39/EC of the European Parliament and of the Council. 2014.

[5] A.W. Lynch, Proposals for a Directive on Markets in Financial Instruments Repealing Directive 2004/39/EC: European Commission, 2011.

[6] European Union, Regulation (EU) No 596/2014 of the European Parliament and of the Council. 2014.

[7] European Securities and Markets Authority, Guidelines on Systems and Controls in an Automated Trading Environment for Trading Platforms, Investment Firms and Competent Authorities (ESMA), 2011.

[8] London Stock Exchange, FIX Trading Gateway (FIX 5.0). London: London Stock Exchange, 2012.

[9] Borsa Italiana SpA, Rules of the Markets Organised and Managed. 2016.

[10] M. Avellaneda, Algorithmic and High-Frequency Trading: An Overview. New York, NY: Quant Congress USA, 2011.

[11] European Securities and Markets Authority, Automated Trading Guidelines. ESMA, 2015.

[12] T. Hendershott, C.M. Jones, and A.J. Menkveld, "Does algorithmic trading improve liquidity?," J. Finance, vol. 66, no. 1, pp. 1-33, Aug 2011.

[13] B. Biais and B.P. Woolley, High Frequency Trading. Toulouse: Toulouse University, IDEI, 2011.

[14] J. Brogaard, T. Hendershott, and R. Riordan, High Frequency Trading and Price Discovery, Working Paper Series No 1602. Frankfurt, Germany: European Central Bank, 2013.

[15] European Securities and Markets Authority, High-Frequency Trading Activity in EU Equity Markets. 2014. 
[16] V. Caivano, S. Ciccarelli, G.D. Stefano, M. Fratini, G. Gasparri, M. Giliberti, N. Linciano, and I. Tarola, High Frequency Trading: Definition, Effects, Policy Issues, Discussion Paper No. 5. Rome, Italy: CONSOB (Commissione Nazionale per le Societá e la Borsa), 2012.

[17] P. Gomber, B. Arndt, M. Lutat, and T. Uhle, High-Frequency Trading. SSNT, 2011.

[18] I. Aldridge, High-Frequency Trading, A Practical Guide to Algorithmic Strategies and Trading Systems. Hoboken, NJ: John Wiley \& Sons, 2010.

[19] E. Boehmer, International Evidence on Algorithmic Trading. SSRN, 2012.

[20] J. Xu, Optimal Strategies of High Frequency Traders, Job Market Paper.

[21] ISDA, Regulation Automated Trading. New York, United States: ISDA, 2016.

[22] J. Qi, "Risk measurement with high-frequency data - value-at-risk and scaling law methods," Ph.D thesis, Center Comput. Finance Econ. Agents, Univ. Essex, Colchester, UK, 2011.

[23] The Government Office for Science, Foresight: The Future of Computer Trading in Financial Markets. London, UK: The Government Office for Science, 2012.

[24] V. Caivano, The Impact of High-Frequency Trading on Volatility. Evidence from the Italian Market. Rome, Italy: Commissione Nazionale per le Società e la Borsa, 2015.

[25] G. Carlone, "High frequency trading an analysis regarding volatility and liquidity starting from a base case of algorithms and a dedicated software architecture," in 2014 IEEE Conf. Comput. Intell. Financial Eng. Econ. (CIFEr), London, UK, 2014, pp. 210-214.

[26] V. van Kervel, "Liquidity: What you See is what you Get?," Int. J. Banking Finance, May 2012 .

[27] K. Down, An Introduction to Market Risk Measurement. Hoboken, NJ: John Wiley \& Sons, 2002.

[28] W. Surapaitoolkorn, "Market risk VaR historical simulation model with autocorrelation effect: A note," Int. J. Banking Finance, vol. 6, no. 2, pp. 155-165, Jan 2009.

[29] K. Dowd, Measuring Market Risk. Hoboken, NJ: John Wiley \& Sons, 2007.

[30] Basel Committee on Banking Supervision, Minimum Capital Requirements for Market Risk. Basel, Switzerland: BCBS, 2016.

[31] C. Alexander, Quantitative Methods in Finance, Market Risk Analysis. Hoboken, NJ: John Wiley \& Sons, 2008.

[32] H. Li, X. Fan, Y. Li, Y. Zhou, Z. Jin, and Z. Liu, Approaches to VaR. Stanford, CA: Stanford University.

[33] S. Corkalo, "Comparison of value at risk approaches on a stock portfolio," Croatian Oper. Res. Rev., vol. 2, no. 1, pp. 81-90, Feb 2011.

[34] P. Gurrola-Perez and D. Murphy, Filtered historical simulation Value-at-Risk models and their competitors, Working Paper No 525. Bank of England, London, UK, 2015. 
[35] G. Mentel, "Parametric or Non-Parametric Estimation of Value-At-Risk," Int. J. Bus. Manage., vol. 8, no. 11, p. 103, May 2013.

[36] Basel Committee on Banking Supervision, Analysis of the Trading Book Hypothetical Portfolio Exercise. Basel, Switzerland: BCBS, 2014.

[37] A.W. Lynch, "Portfolio choice and equity characteristics: Characterizing the hedging demands induced by return predictability," J. Financial Econ., vol. 62, no. 1, pp. 67-130, Oct 2001 .

[38] J. Fogarty, Rethinking Wine Investment in the UK and Australia, AAWE Working Paper No. 57. American Association of Wine Economists, 2007.

[39] ESMA71-99-1284, ESMA finds continued high risks as financial markets remain highly volatile , Press Releases , Risk Analysis \& Economics , Markets Infrastructure Investors , Press Release, 2020.

[40] ESMA71-99-1270, ESMA report values EU Alternative Investment Funds at €5.8 trillion Fund Management, Press Releases, Risk Analysis \& Economics , Markets Infrastructure Investors , Press Release, 2020.

[41] ESMA71-99-1138, ESMA issues four positive opinions on national product intervention measures, MiFID , Investor Protection, Press Releases, Press Release , 2019.

[42] European Union, Commision Regulation , Commission Delegated Regulation (EU) 2019/443 of 13 February 2019 amending Delegated Regulation (EU) 2017/588 , 2019 .

[43] G Carlone, T\&F CRC PRESS , Introduction to Credit Risk, Book ISBN : 9780367478490 , Ebook ISBN : 9781003036944 , FINANCE , United Kingdom, London, $\operatorname{dec} 2019$.

TABLE OF CONTENT

INTRODUCTION

PORTFOLIO MAIN CHARACTERISTIC STRUCTURE OF LONDON STOCK EXCHANGE COMMODITY COUNTERPARTY

MARKET VALUE AT RISK ANALYSIS FROM A POINT OF VIEW OF SUPERVISORS

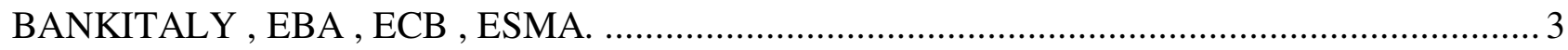

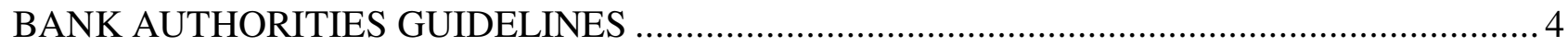

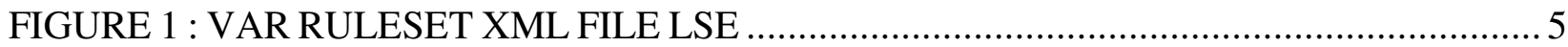

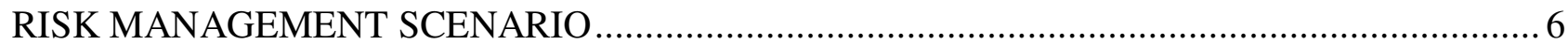

MATHEMATICAL POINT OF VIEW OF MARKET VALUE AT RISK, PARAMETRIC APPROACH OF VAR, SEMI PARAMETRIC APPROACH OF VAR, NON PARAMETRIC APPROACH OF VAR

I. PARAMETRIC APPROACH OF VAR .................................................................... 8

II. SEMI PARAMETRIC APPROACH OF VAR ............................................................. 10

III. NON PARAMETRIC APPROACH OF VAR ............................................................. 11 
VAR DISTORSIONS USING DIFFERENTS CONFIDENCE LEVELS REAL PORTFOLIO CASE 244 SIMULATION DATES AND PRICES

MAX PRICE DISTORSION CLOSE PRICE OPEN PRICE FIRST COMMODITIES AND PORTFOLIO. PRICES BASE CASE OF 37 PRICE OBSERVATIONS AND 49 PRICE OBSERVATIONS. REAL LARGE CASE OF 244 PRICES USED FOR VAR DATA

FIGURE 3 : FIRST COMMODITY 37 CLOSE PRICES SCENARIO …........................... 15

FIGURE 4 : FIRST COMMODITY 49 CLOSE PRICES SCENARIO …........................... 16

FIGURE 6 : PORTFOLIO SECOND COMMODITY 244 CLOSE PRICES SCENARIO .......... 17 COMPLETE SCENARIO OF MAX PRICE DISTORTIONS. COMMODITY PRICE MANIPULATION DISTORTIONS IN RISK, MANAGEMENT, RISK MANAGEMENT.

FIGURE 7 : FIRST LSE COMMODITY 244 HIGH PRICES AND LOW PRICES IN ONE YEAR

FIGURE 8: FIRST COMMODITY LSE 244 HIGH PRICES AND LOW PRICES, MAX

DISTORTION, IN ONE YEAR 18

FIGURE 9: COMMODITY PORTFOLIO LSE CLOSE PRICE MAX DISTORTION, IN ONE YEAR

EMPIRICAL MARKET MODEL GENERALIZATION IN LONDON IN EUROPE AND WORLD

I. EMPIRICAL MARKET MODEL in London Stock Exchange Scenario 19

FIGURE 10: SCENARIO EMPIRICAL MARKET MODEL REPRESENTATION 20

II. EMPIRICAL MARKET MODEL in European Scenario 20

FIGURE 11: SCENARIO EMPIRICAL MARKET MODEL EUROPEAN SCENARIO

III. EMPIRICAL MARKET MODEL in a World Scenario

FIGURE 12: SCENARIO EMPIRICAL MARKET MODEL WORLD SCENARIO

CONCLUSION IN POINTS OF EMPIRICAL MARKET MODEL GENERALIZATION 22 CONCLUSION, EU REGULATION EMPIRICAL MARKET MODEL FOR DATASET CHOICE VAR DATA GENERATION VAR DATA CHOICE 22 
Figures

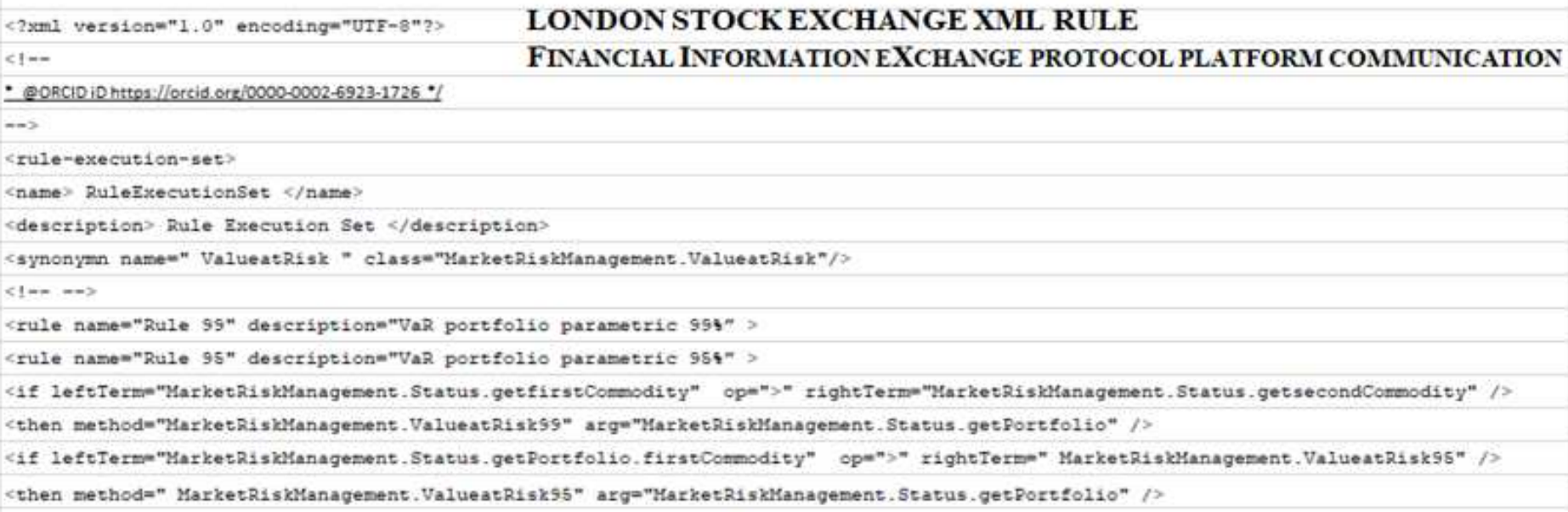

Figure 1

VAR RULESET XML FILE LSE

VAR DATA GENERATED AND DISTORSION

244 NUMBER OF SIMULATION DATES

APPROACH OF VAR MEASURE IN A PERIOD OF ONE YEAR

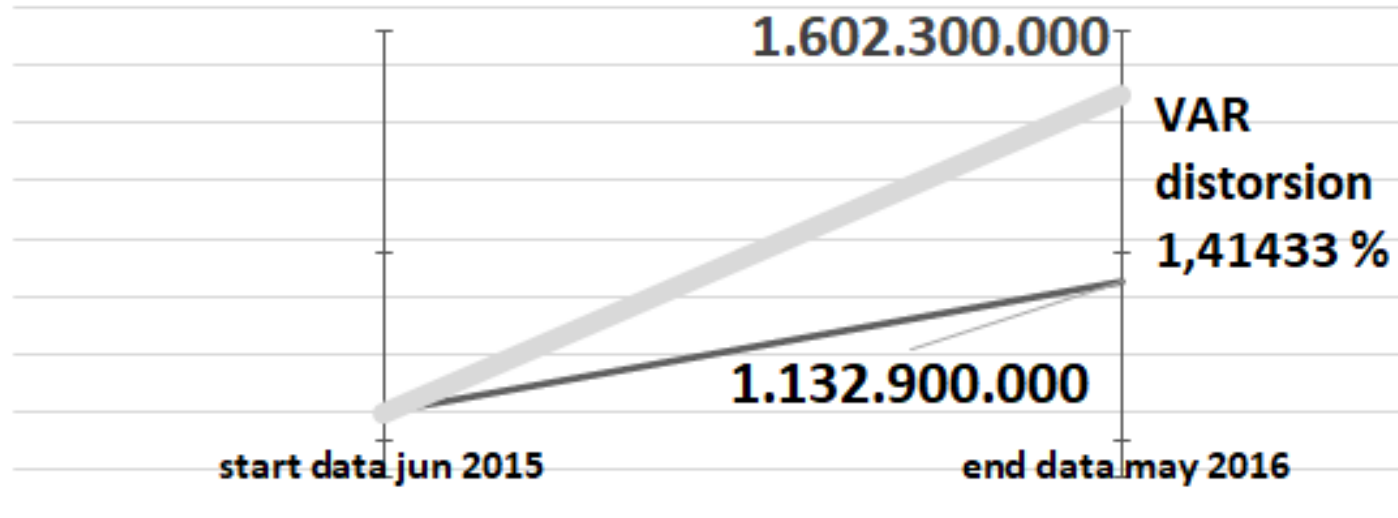

—VAR $95 \% \quad$ VAR $99 \%$

Figure 2

INITIAL VAR DATA GENERATED AND DISTORSION REQUIREMENTS 


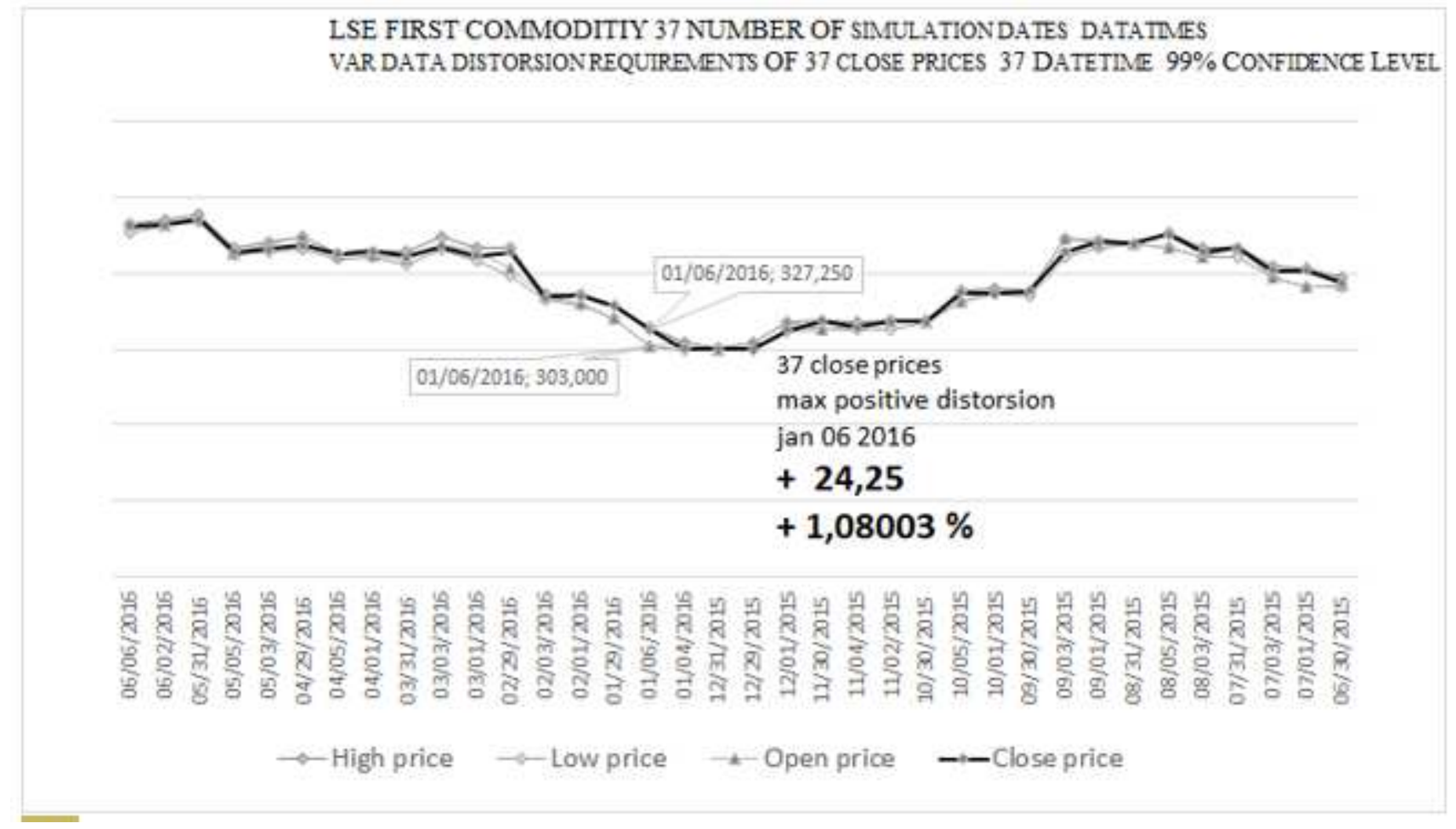

\section{Figure 3}

FIRST COMMODITY 37 CLOSE PRICES SCENARIO

\section{LSE FIRST COMMODITIY 49 NUMBER OF SIMULATION DATES DATATIMES \\ VAR DATA DISTORSION REQUIREMENTS OF 49 CLOSE PRICES 49 DATETIME $99 \%$ CONFIDENCE LEVEL}

600

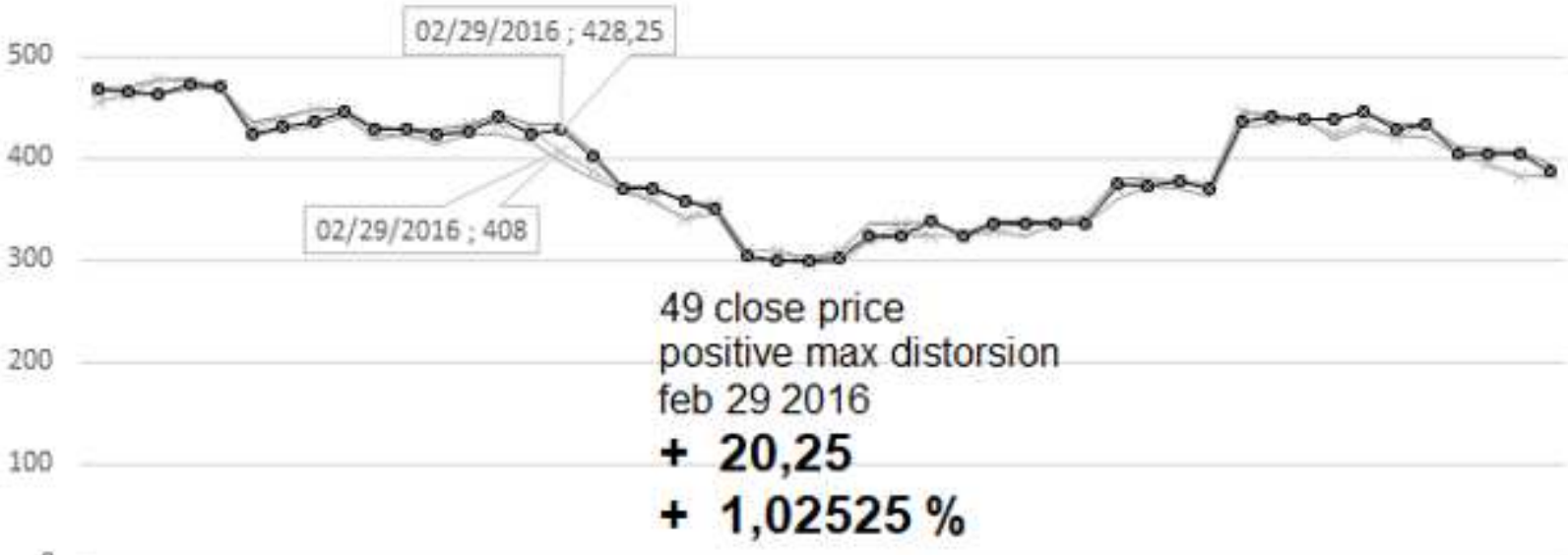

0

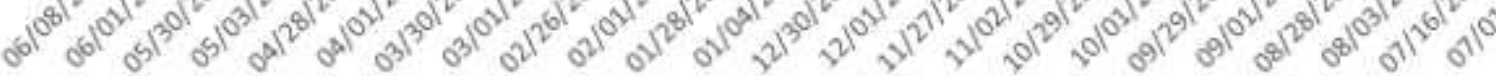

- High price - Low price $\quad$ Open price $\rightarrow$ CLOSE PRICE

\section{Figure 4}




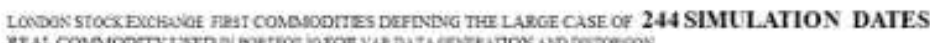

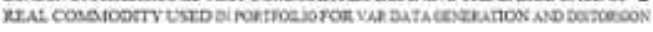

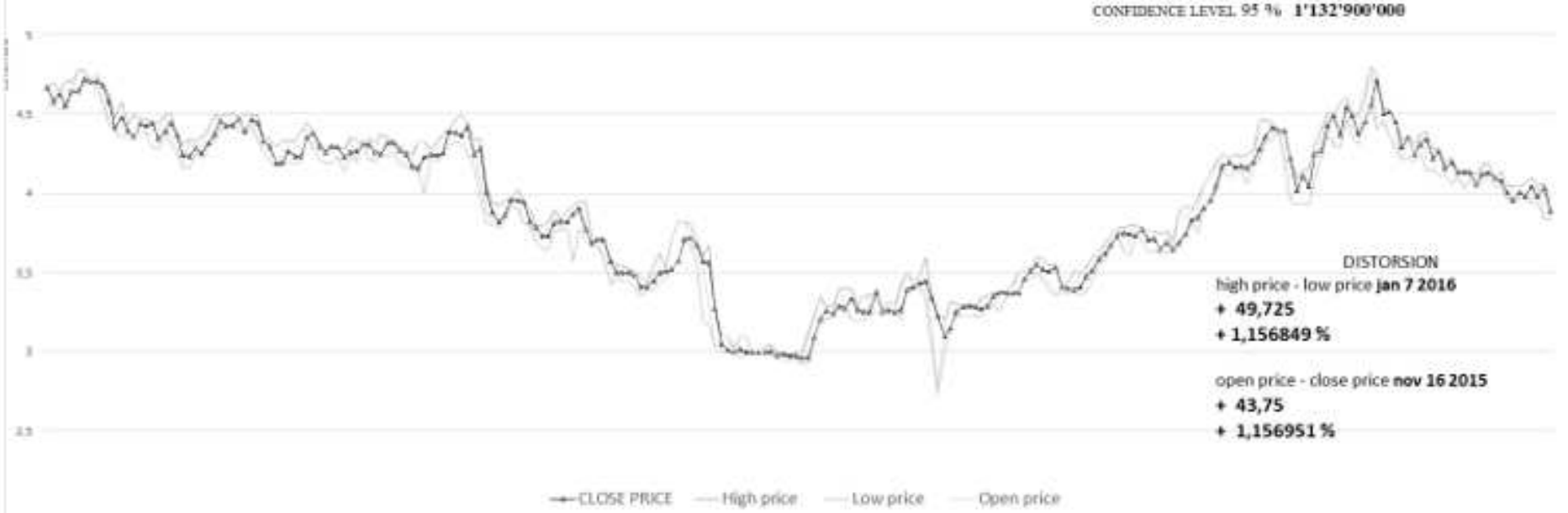

Figure 5

PORTFOLIO FIRST COMMODITY 244 CLOSE PRICES SCENARIO

LSE SECOND COMMODITIES DEFINING THE LARGE CASE OF 244 SIMULATION DATES VAR DATA COMMODITIES PORTFOI REAL SECOND COMMODITY USED IN PORTFOLIO FOR VAR DATA GENERATION AND DISTORSION CONFIDENCE LEVEL $99 \% \mathbf{1}^{\prime} 602 \mathbf{2}^{\prime} \mathbf{3 0 0} 000$ CONFIDENCE LEVEL $95 \%$ 1'132'900'000

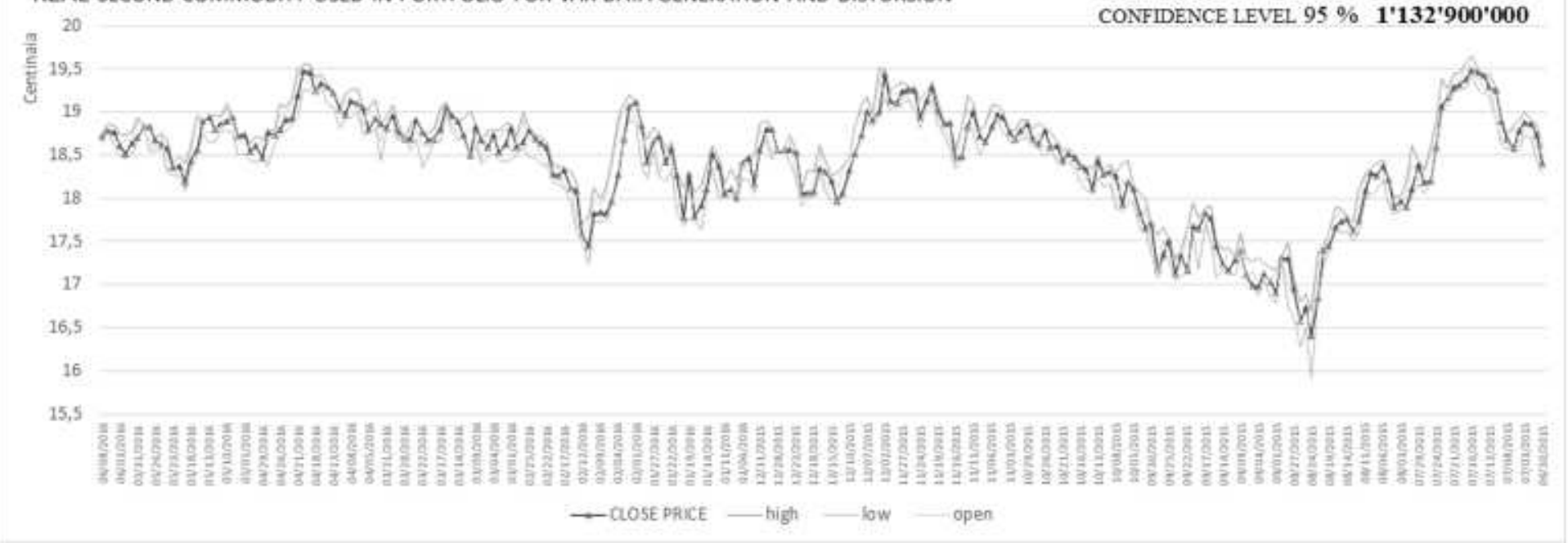

Figure 6

PORTFOLIO SECOND COMMODITY 244 CLOSE PRICES SCENARIO 
first Commodity prices one year

\section{London Stock Exchange}

600

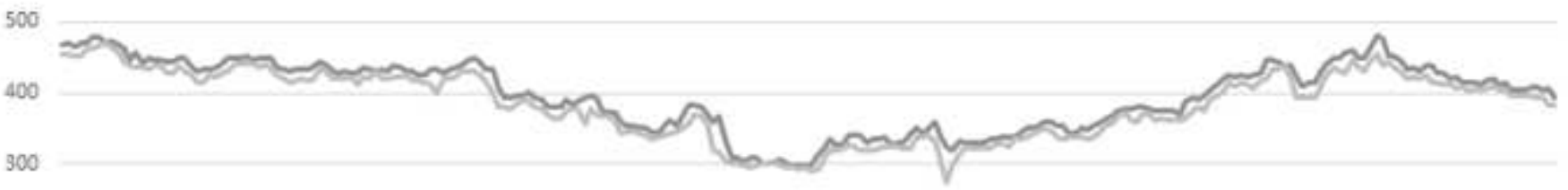

200

100

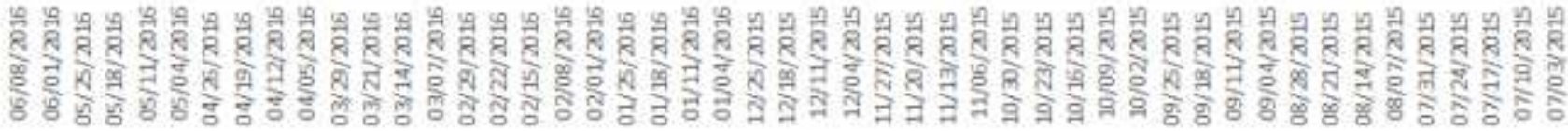

—High price —Low price

\section{Figure 7}

FIRST LSE COMMODITY 244 HIGH PRICES AND LOW PRICES IN ONE YEAR

LONDON STOCK EXCHANGE FIRST COMMODITIES DEFINING THE LARGE CASE OF 244

SIMULATION DATES

REAL COMMODITY USED IN PORTFOILIO FOR VAR DATA GENERATION AND DISTORSION

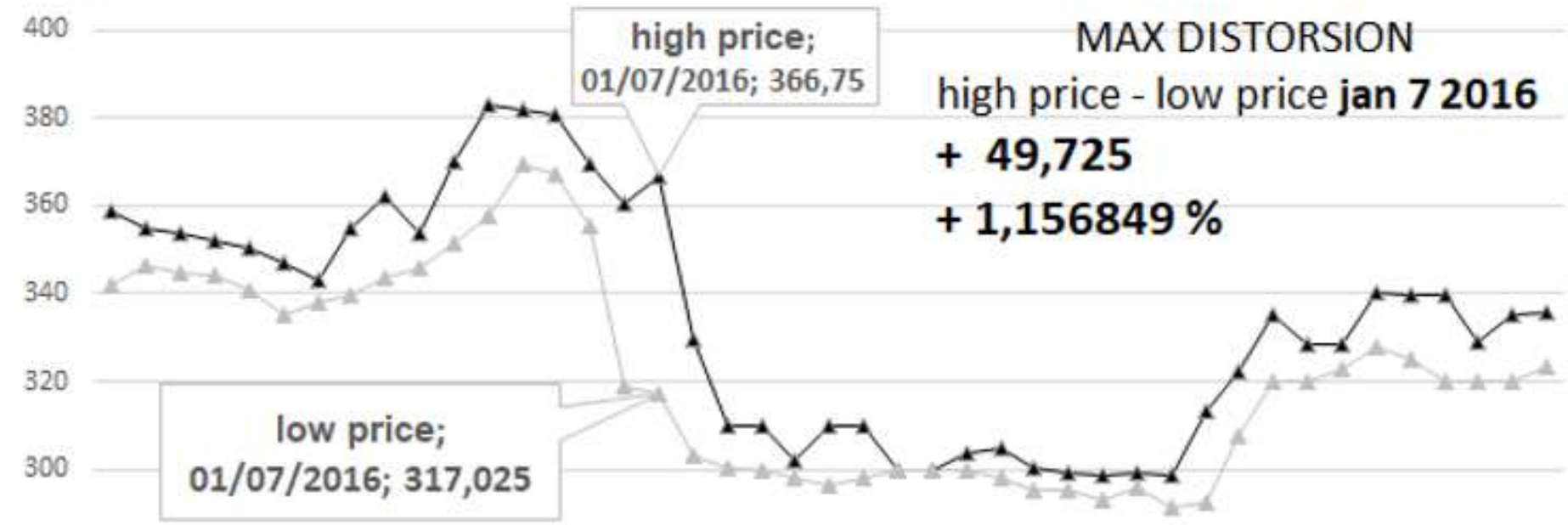

280
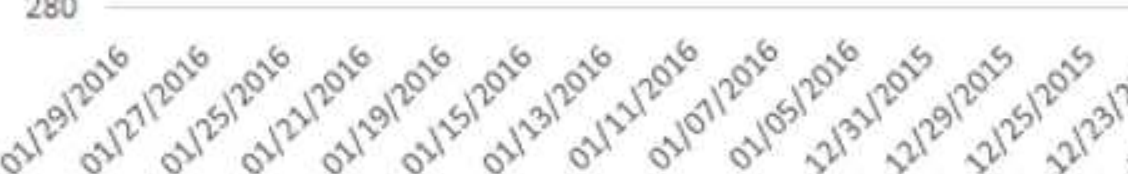

\section{os}

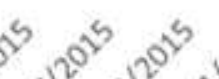

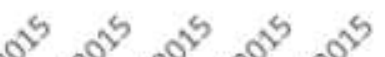




\section{first commodity CLOSE PRICE MAX DISTORTION \% distorsion $=$ close price - open price}

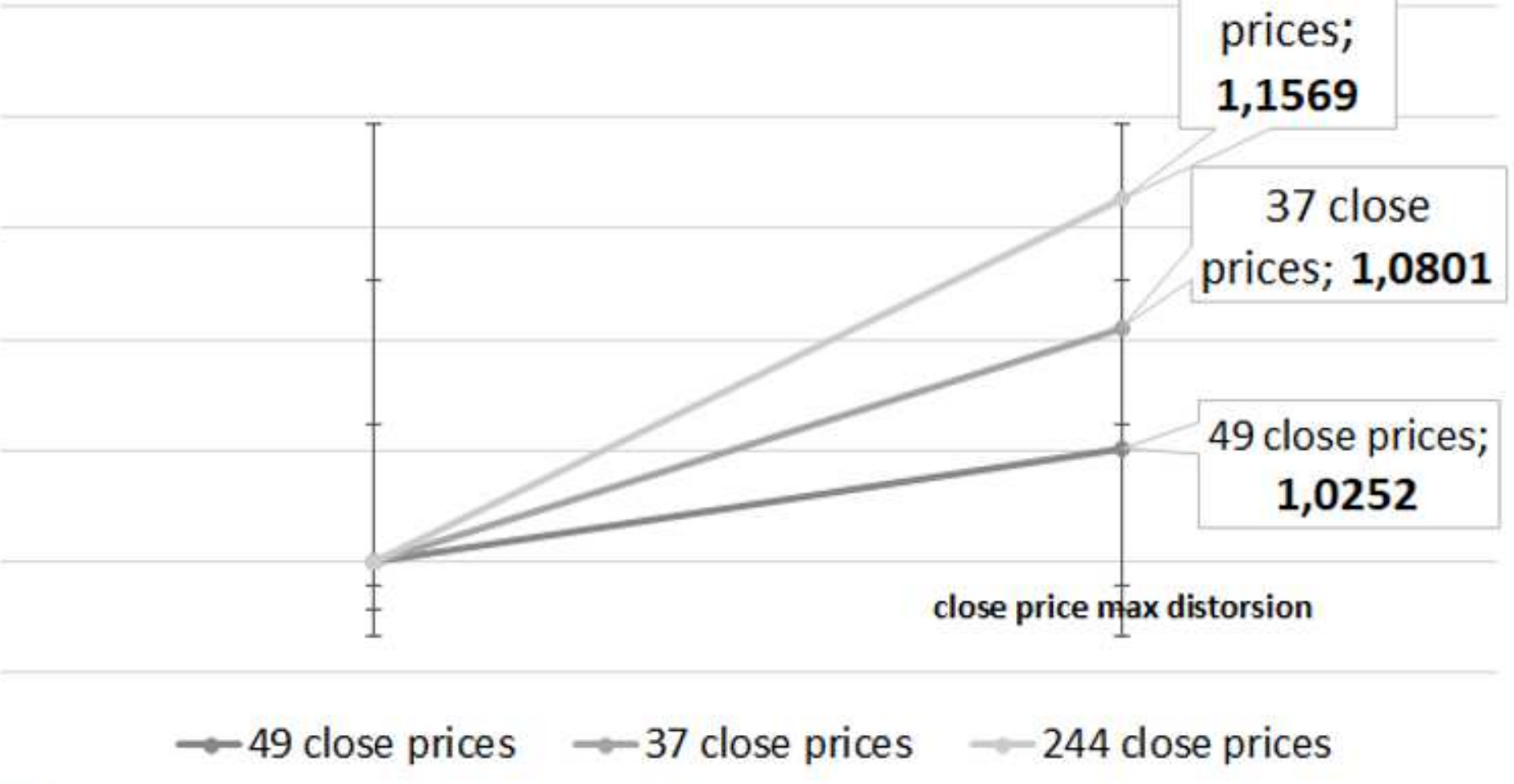

Figure 9

COMMODITY PORTFOLIO LSE CLOSE PRICE MAX DISTORTION, IN ONE YEAR

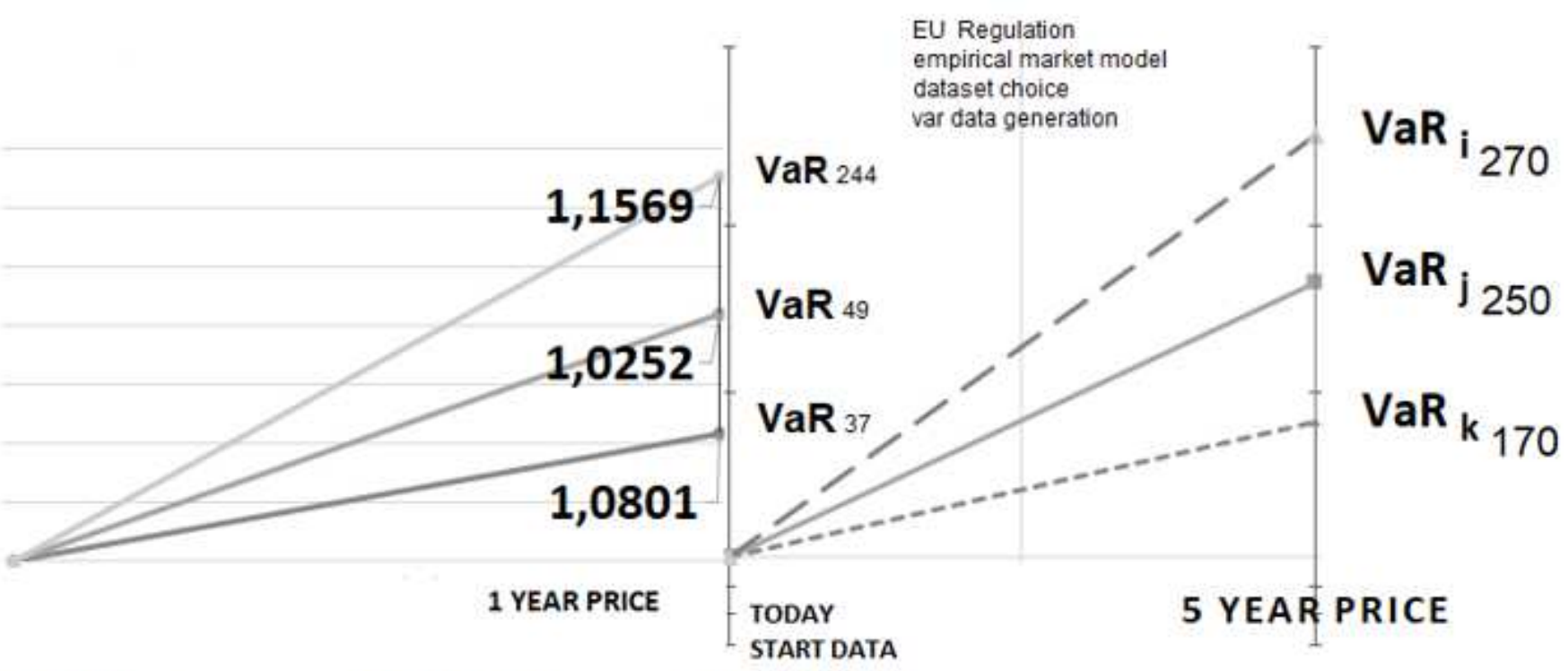

$\rightarrow 37$ dataset $\rightarrow 49$ dataset $\rightarrow 244$ dataset

$-\sim 170$ dataset $\because-250$ dataset $\rightarrow-270$ dataset

Market Risk Model 
Figure 10

SCENARIO EMPIRICAL MARKET MODEL REPRESENTATION

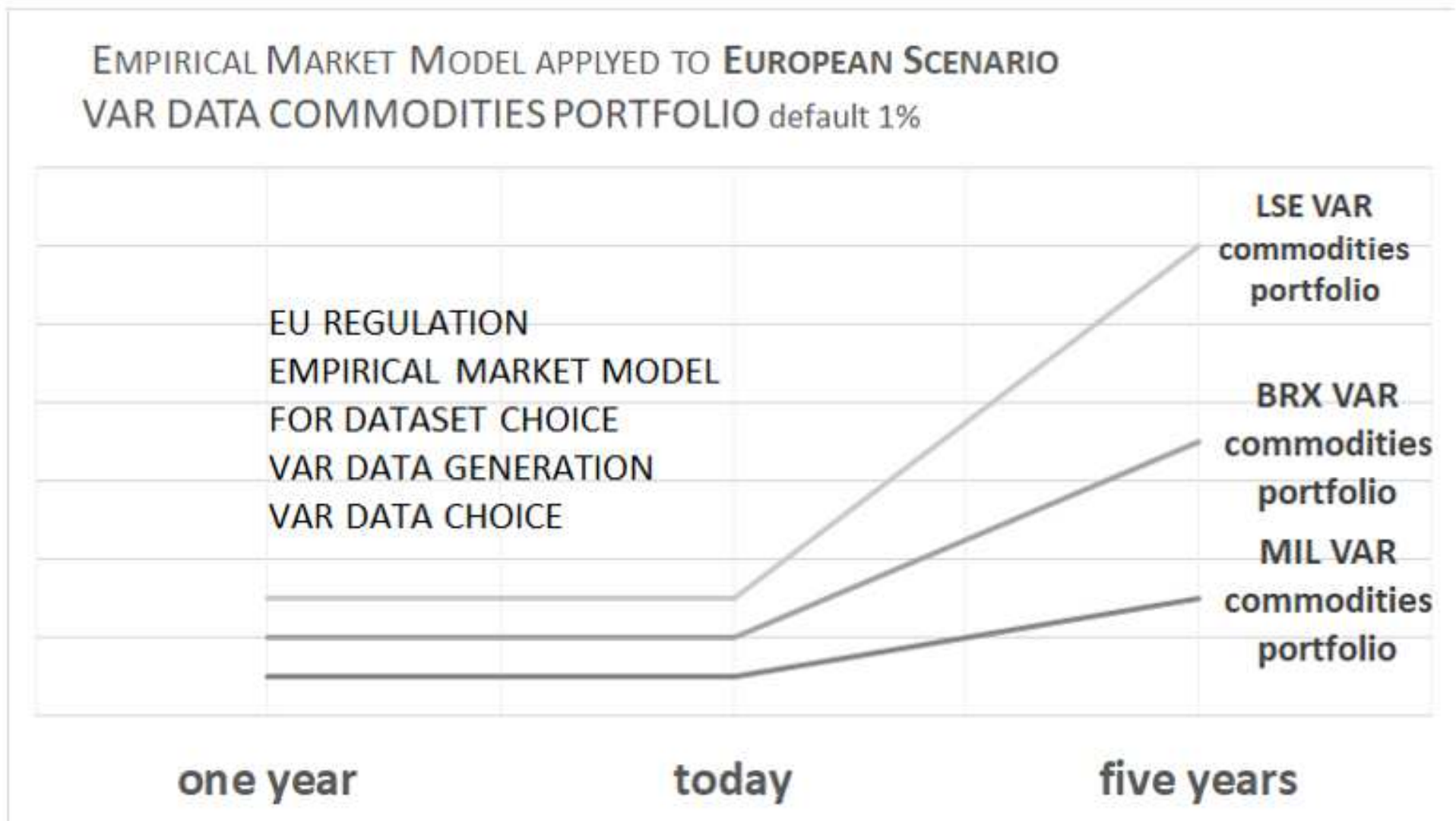

Figure 11

SCENARIO EMPIRICAL MARKET MODEL EUROPEAN SCENARIO 
EMPIRICAL MARKET MODEL APPLYED TO WORLD SCENARIO

VAR DATA COMMODITIES PORTFOLIO default $1 \%$

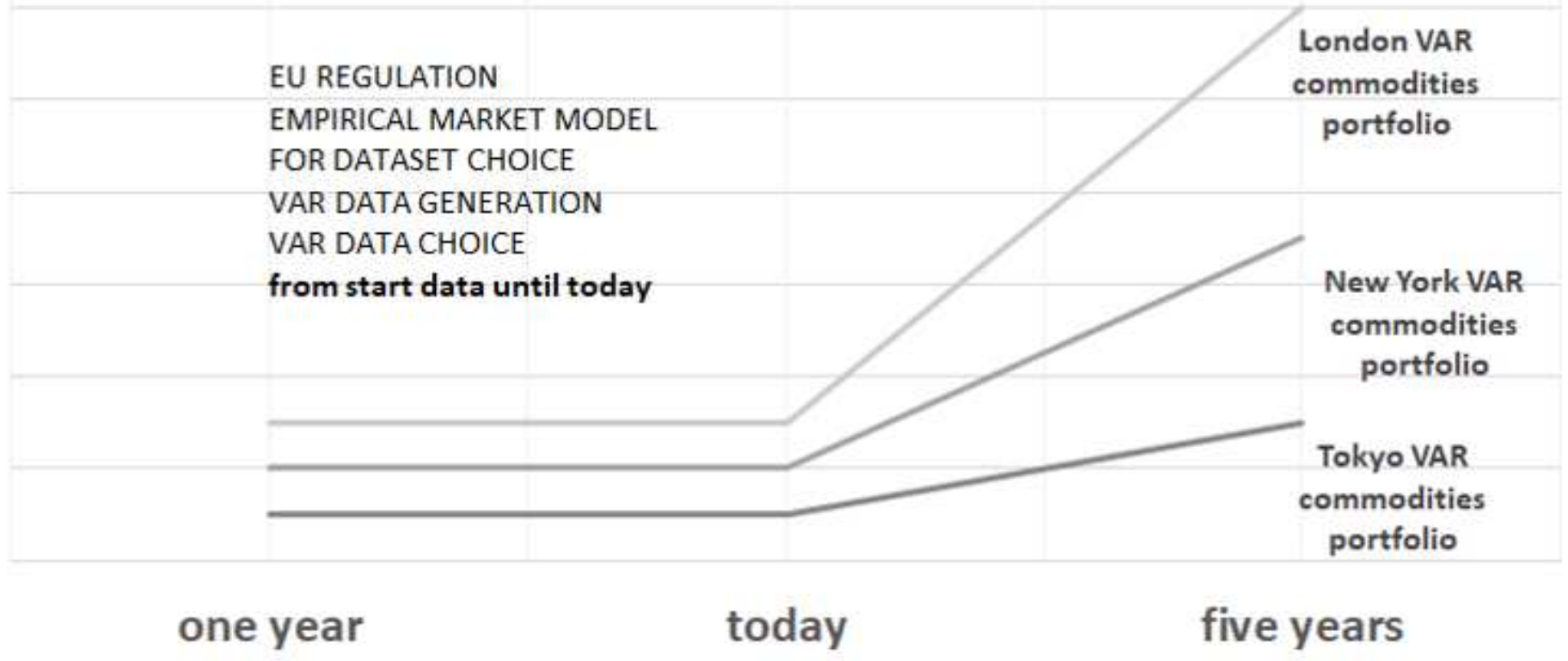

Figure 12

SCENARIO EMPIRICAL MARKET MODEL WORLD SCENARIO 